
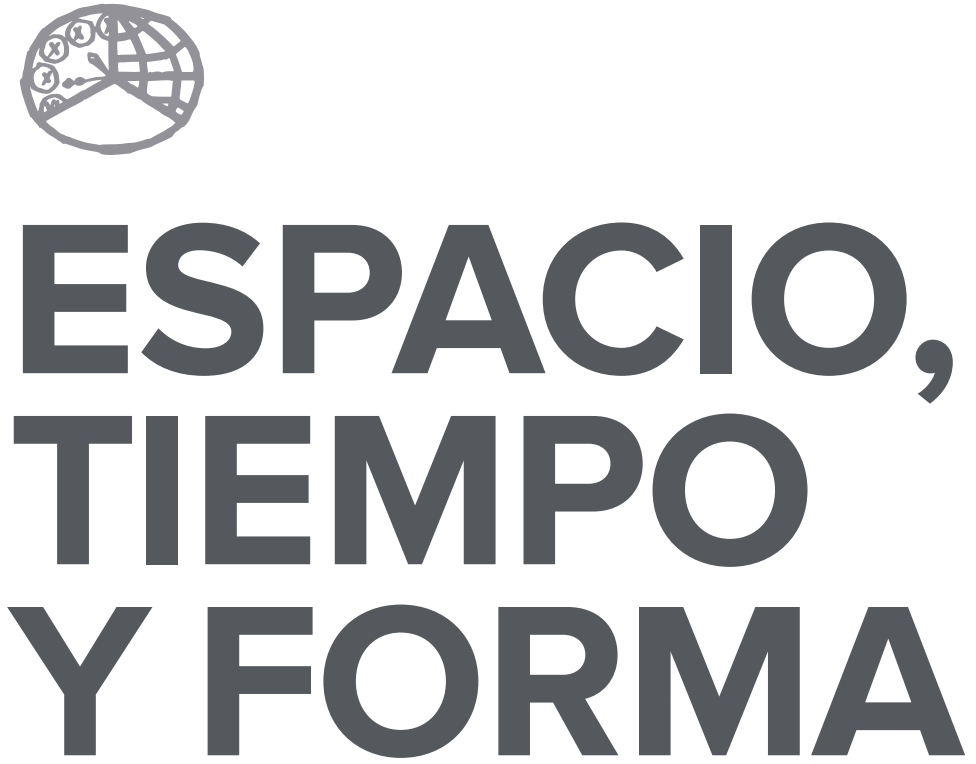

AÑO 2020

ISSN 0214-9745

E-ISSN 2340-1362

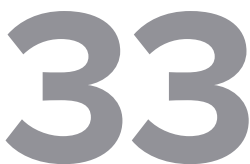

SERIE III HISTORIA MEDIEVAL

REVISTA DE LA FACULTAD DE GEOGRAFÍA E HISTORIA 



\section{ARTÍCULOS · ARTICLES}





\title{
LA MEMORIA DEL LINAJE ARIAS DÁVILA EN LA COFRADİA Y HOSPITAL DE SAN COSME Y SAN DAMIÁN DE VALLADOLID (SIGLOS XV A XVII)
}

\section{THE MEMORY OF THE ARIAS DÁVILA LINEAGE AND THE CONFRATERNITY AND HOSPITAL OF SAINTS COSME AND DAMIAN OF VALLADOLID (FIFTEENTH TO SEVENTEENTH CENTURIES)}

\author{
María Eugenia Contreras Jiménez ${ }^{1}$
}

Recepción: 2019/05/31 · Comunicación de observaciones de evaluadores: 2019/07/30 . Aceptación: 2019/09/13

DOI: http://dx.doi.org/10.5944/etfiii.33.2020.26734

\section{Resumen}

El estudio aborda la relación mantenida por un linaje castellano y una cofradía y su hospital, así como el cambio que paralelamente se produce en la apreciación de la propia memoria del grupo familiar, desde categorías individuales a grupales, a medida que evolucionan los dos mayorazgos instituidos en la rama masculina de los Arias Dávila. Las fuentes, en gran parte inéditas, permiten ver cómo Pedrarias Dávila, gobernador en América, enalteciendo el origen de su propia rama, el obispo don Juan Arias, estableció las bases del proceso analizado.

\section{Palabras clave}

Obispo de Segovia; Pedrarias Dávila; cofradía religiosa; nobleza; mayorazgo; patronazgo; archivo de los condes de Puñonrostro.

\section{Abstract}

This study examines the relationship between a Castilian lineage and a confraternity and its hospital, as well as the change that took place at the same time, in the selfassessment of the family's memory, both on an individual and a group level, in the

1. Doctora en Historia (UCM). Asesora del Área Social del Centro de Formación e Innovación Educativa (CFIE) de Segovia. C.e.: mecontrerasj@yahoo.es 
development of the entailed estates (mayorazgos) of the male branch of the Arias Dávila lineage. The documentary records, many of which are unpublished, allow us to establish how Pedrarias Dávila, governor in America, laid the foundations for his family's memory by extolling the origin of his branch founded by bishop Juan Arias.

Keywords

Bishop of Segovia; Pedrarias Dávila; Religious Confraternity; Nobility; Entailed Estate (mayorazgo); Archive of the Count of Puñonrostro. 
El archivo de los Condes de Puñonrostro custodia varios instrumentos relativos a la cofradía y hospital vallisoletanos de los «bienaventurados mártires San Cosme y San Damián»²; de aquéllos sólo uno había sido dado a conocer en líneas generales dentro de diversos contextos historiográficos ${ }^{3}$.

El objetivo del trabajo es presentar, a través de fondos inéditos del mencionado archivo y siguiendo un criterio cronológico, cómo una familia noble y una cofradía entendieron las relaciones de benefactor y beneficiados a lo largo de casi dos siglos, cómo éstas se fueron modificando, qué elementos presentaron y cómo se construyó una memoria del linaje ${ }^{4}$. En consecuencia, al analizar un fenómeno concreto desde la visión del grupo social que lo produce, se hará una aproximación a los intereses de unos miembros del estamento nobiliar castellano desde el siglo XV al XVII.

El condado de Puñonrostro fue concedido en 1523 a Juan Arias de Ávila (†1538). Este personaje era nieto del famoso contador mayor de Castilla Diego Arias Dávila (†I466) quien junto con su esposa Elvira González (†I463) estableció el mayorazgo definitivo en I462. Pedro Arias (†I476), hijo legitimo varón mayor, recibió dicho

2. Deseo agradecer las facilidades de acceso a la documentación del archivo a don Manuel Arias Dávila y Balmaseda, actual cabeza de la Casa de Puñonrostro, y a su archivero, don Luis Barrio Moya, sin cuyas ayudas no habría sido posible la realización de este artículo.

3. Alcocer y Martínez, Manuel: «El Rosarillo», Boletín de la Comisión de Monumentos Históricos y Artísticos de la provincia de Valladolid, año III 5 [1927], pp. 33-47, en especial p. 7; del mismo autor El Rosarillo. Estudio histórico de la cofradía de San Cosme y San Damián antes y después de su unión con la de Nuestra Señora del Rosario, Valladolid, Casa Social Católica, (s.a.), p. 35, y AGApIto y Revilla, Juan: Las calles de Valladolid. Nomenclator histórico (1937), Valladolid, (1937), facsímil 1982, p. 389 se hicieron eco de un concierto fechado en 16 de julio de 1499 entre Pedrarias Dávila, más tarde famoso gobernador en América, y la cofradía. Con posterioridad ARAM, Bethany: Leyenda negra y leyendas doradas en la conquista de América. Pedrarias y Balboa, Madrid, Fundación Jorge Juan-Marcial Pons, 2008, pp. 45-6 fechó otros acuerdos relacionados con el anterior a 22 de abril de 1499 y 19 de marzo de 1511 . Tanto las obras de Alcocer como la de Agapito constituyen el punto de partida de una tradición bibliográfica que llega a nuestros días, cuyo interesante desarrollo sobrepasa los límites del presente trabajo, pero constata la devoción vallisoletana a los Mártires desde el siglo XIII. Las mismas razones de espacio obligan a obviar cuestiones como la identidad social y religiosa de la cofradía en Valladolid a lo largo de dichos siglos o profundizar en otras como las relaciones entre los diversos Arias y los miembros poderosos o no de la cofradía, el hospital y los vallisoletanos.

4. A pesar de la sugerente bibliografía de análisis de las cofradías, existe una laguna en lo que se refiere a las conexiones mantenidas entre éstas y los linajes. De ahí el interés de trabajos que se aproximan al tema como los de Rodríguez Morales, Carlos: «Iglesia y sociedad en La Laguna durante el Antiguo Régimen. La cofradía de Jesús Nazareno y el patronato de los Salazar de Frías», Revista de Historia Canaria, 183 (abril, 2001), pp. 275-293; SILVA PRADA, Natalia: «La dote en la familia devocional: estrategias familiares en la cofradía novohispana, 1538-1680», Anuario de historia regional y de las fronteras, vol. 6, 1 (2001), pp. 419-445; CANTERO MuÑOZ, Antonio: «El patronato de Don Luis de Tapia y Paredes sobre la ermita de San Lázaro de Trujillo a partir de 1630 y estatutos de su cofradía», XXXVII Coloquios Históricos de Extremadura: dedicados a la Guerra de la Independencia en Extremadura. Trujillo del 22 al 28 de septiembre de 2008, 2009, vol. 2, pp. 439-462; Rodríguez EsPINOZA, Arnaldo: «Vinculaciones religiosas, milicias y cabildo: el linaje Viales Briceño en el partido de Nicoya (1768-1824)», Espiga, 30 (julio-diciembre 2015), pp. 83-96, aunque en ellos la tipología de cofradía religiosa, el patronato, el tiempo y el espacio presenten notables diferencias. En cuanto a relaciones entre este tipo de agrupación familiar e Iglesia, dentro de la sugerente bibliografía que hoy existe, siguen siendo básicos los de JARA FUENTE, José Antonio: «Muerte, ceremonial y ritual funerario: Procesos de cohesión intraestamental y de control social en la alta aristocracia del Antiguo Régimen (Corona de Castilla, siglos XV-XVIII)», Hispania. Revista Española de Historia, 194 (1996), pp. 861-883 y de CARrasco Martínez, Adolfo, «Los Mendoza y lo sagrado. Piedad y símbolo religioso en la cultura nobiliaria», Cuadernos de Historia Moderna, 25 (2000), pp. 233-269. Para la memoria del linaje véanse los editados por DAcosta, Arsenio, Prieto LASA, José Ramón, DíAz de DuRANA, José Ramón (eds.): La conciencia de los antepasados. La construcción de la memoria de la nobleza en la Baja Edad Media, Madrid, Marcial Pons Historia, 2014, en especial el de Jular Pérez-Alfaro, Cristina: «La importancia de ser antiguo: Los Velasco y su construcción genealógica», pp. $201-236$. 
mayorazgo y se convirtió así en el creador de la rama masculina del linaje, siendo don Juan Arias (†I497) el hijo dedicado a la Iglesia e Isabel Arias (†I472) el punto de partida de la rama femenina de la familia. Por su parte, don Juan, obispo de Segovia, otorgó testamento en 1497 nombrando heredero universal de sus bienes vinculados a su sobrino Pedrarias, hijo segundón de su hermano Pedro y, con el paso del tiempo, futuro gobernador en América 5 .

Así, en la rama masculina de los Arias Dávila se formaron dos mayorazgos, el proveniente de Diego Arias (que recayó en Juan, primer conde de Puñonrostro), y el que lo hacía de los bienes del prelado don Juan, constituido por Pedrarias. Sin embargo, el caprichoso devenir de los tiempos hizo que ambos volvieran a reunirse en un solo varón a finales del siglo XVI, con lo que mayorazgos y patronazgos, patrimonio y memoria del linaje pasaron a estar dirigidos por la misma persona. Será en la decimoséptima centuria cuando el conde de Puñonrostro replantee las señas de identidad familiares.

\section{DON JUAN ARIAS DE ÁVILA, OBISPO DE SEGOVIA Y OIDOR DE LA REAL AUDIENCIA DE VALLADOLID, Y LA COFRADÍA DE SAN COSME Y SAN DAMIÁN: 1494 Y 1497}

La compleja figura de don Juan Arias de Ávila tuvo que afrontar el proceso inquisitorial incoado a varios de sus antepasados, causa de su marcha en 1490 a Roma, de donde no regresó vivo ${ }^{6}$.

Desde allí intervino en cuestiones relativas a su familia como el establecimiento en 1494 de una cofradía vinculada al hospital fundado en Segovia por su padre Diego Arias de Ávila; ordenó entonces que tuviera los estatutos de la dedicada a San Cosme y San Damián en Valladolid?

Los nexos con dicha institución exigen retroceder en el tiempo unos treinta años. Tras el fallecimiento en I466 de Diego Arias, su descendencia presenta una cierta bicefalia en los ámbitos de actuación: el mayorazgo y la jefatura familiar pasaron a Pedro Arias mientras el hijo segundón, don Juan Arias, contaba con poderes emanados de su condición de eclesiástico.

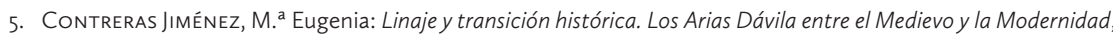
Universidad Complutense de Madrid, (2018), pp. 247-337.

6. Diversas facetas del poliédrico personaje fueron tratadas en Segovia en el siglo XV. Arias Dávila: Obispo y Mecenas, Salamanca, Universidad Pontificia de Salamanca, 1998. Una excelente transcripción del proceso fue realizada por Carrete Parrondo, Carlos: Proceso inquisitorial contra los Arias Dávila segovianos: un enfrentamiento social entre judíos y conversos, Salamanca, Universidad de Salamanca-Universidad de Granada, 1986. Véase otros documentos sobre el proceso en BARTolomé Herrero, Bonifacio: «El obispo segoviano Juan Arias Dávila y la Inquisición: una revisión del conflicto y tres documentos inéditos de 1490», Anthologica Annua, 62 (2015), pp. 57-118 y CONTRERAs JimÉnEZ, M. ${ }^{a}$ Eugenia, op. cit., capítulo V.

7. Contreras Jiménez, M. ${ }^{a}$ Eugenia: «La cofradía del hospital de San Antonio en Segovia (1494): Una estrategia de control social para el linaje Arias Dávila», en prensa. 


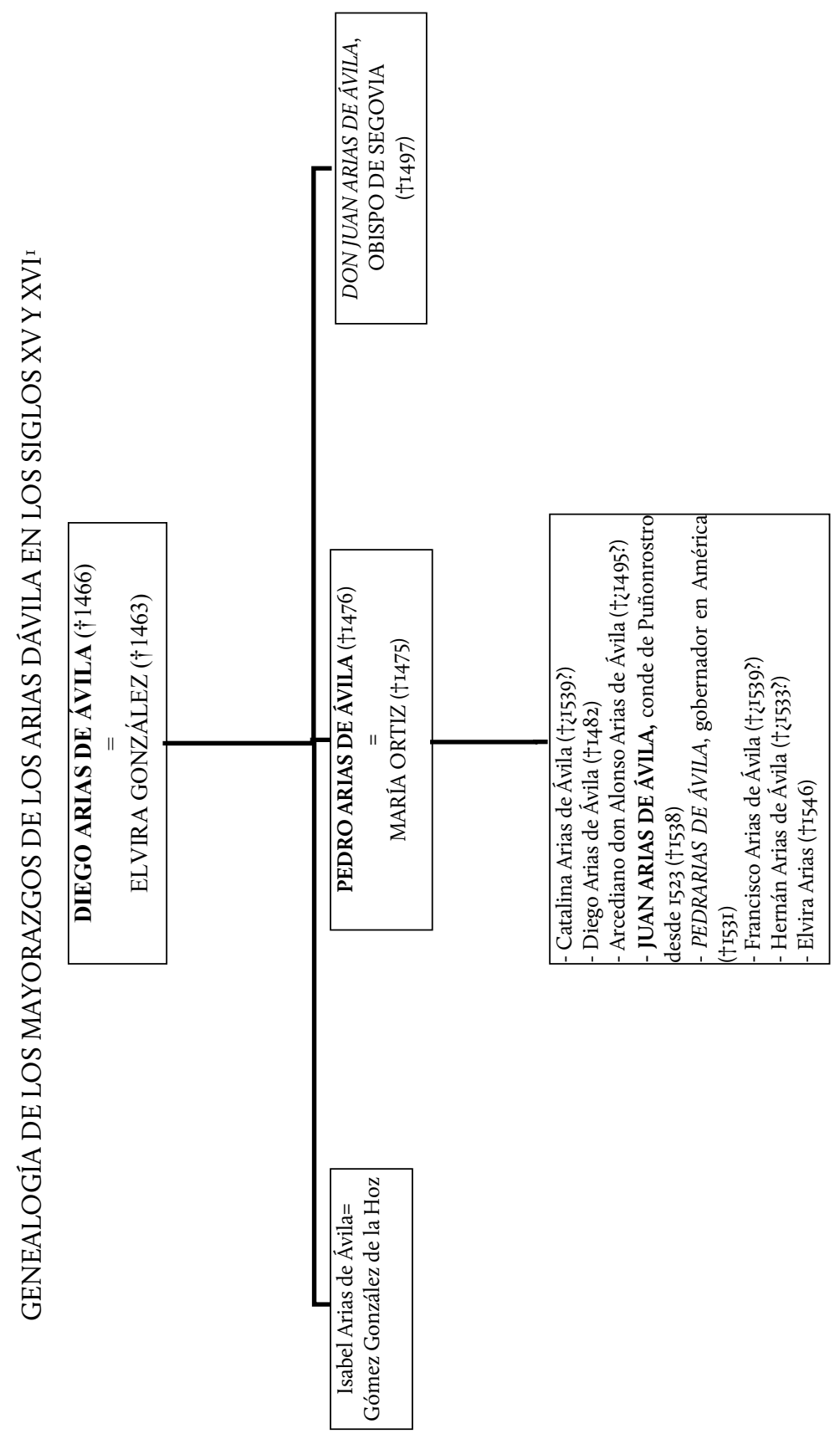

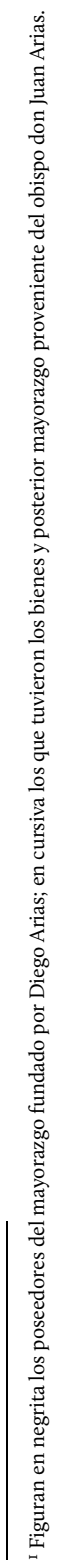


En ese mismo año Enrique IV intentó hacer prisionero a Pedro, que recibió una herida que nunca terminó de cerrar ${ }^{8}$. ¿Podríamos decir que la lesión sería la causante de una ofrenda del clérigo a los santos sanadores Cosme y Damián? Nada se localiza en este sentido en la documentación, incluidos los testamentos de ambos hermanos.

Tengamos presente, asimismo, que don Juan había tenido en la collación de San Esteban de Valladolid unas casas heredadas de su padre que perdió en I468 por su participación en la entrega de Segovia al bando rebelde alfonsino en septiembre del año anterior ${ }^{9}$. A partir de entonces el obispo vive un alejamiento de la figura del monarca, Enrique IV, y de la ciudad del Acueducto, pareciendo probable que se centrase en Turégano, señorío y fortaleza episcopal de su diócesis ${ }^{\mathrm{IO}}$.

Tras la llegada al trono de Isabel I (I474) y la muerte de Pedro Arias (I476), la situación de don Juan mejoró política y socialmente, razón por la que ocupó cargos en la administración civil de la Corona de Castilla; posiblemente éstos le llevaron a reforzar la visión de la importancia administrativa de Valladolid. Éste pudo ser otro motivo para la consolidación de vínculos con dicho ámbito por parte de un personaje que pertenecía a una dinastía de servidores del monarca de Castilla en diversas administraciones.

Al mismo tiempo, su mayor presencia en Segovia hizo que se generasen recelos por el dominio de la ciudad entre él y el matrimonio formado por Andrés Cabrera y Beatriz de Bobadilla: el poder eclesiástico y el poder temporal se enfrentaron hasta que el día 29 de junio de 1489 se hizo público que los padres y abuela materna del prelado iban a ser procesados por la Inquisición, acusados de judaizar. La tensión se relajó en cierta manera cuando don Juan marcha en I490 a Roma para defender su linaje.

En 1497 el obispo de Segovia fue herido en la Ciudad Eterna defendiendo los intereses de Alejandro VI que luchaba contra Esforza ${ }^{\text {II }}$. En octubre don Juan otorga testamento y expresa su deseo de finalizar las obras de reforma emprendidas hacía tiempo en la ermita vallisoletana de San Cosme y San Damián; ahora bien, el testador no menciona estos santos como de su especial devoción ni alude a la cofradía ni al hospital gestionado por ella ${ }^{\mathrm{I2}}$. En el mismo sentido, el hecho de

8. Palencia, Alonso de: Crónica de Enrique IV, Antonio Paz y Melía (ed.), Madrid, B.A.E., CCLVII-CCLIX, 1973-5, III: pp. 211-3 y III: p. 280.

9. Véase para la entrega de Segovia PALENCIA, Alonso de, op. cit., III, p. 230 o Colmenares, Diego de: HISTORIA/ De La Insigne Ciudad/ DE SEGOVIA/y Conpendio de las Historias/ DE CASTILLA/.../EN MADRID POR DIEGO DIEZ. INPRESOR. A COSTA DE SU AVTOR, 1640, cap. XXXII/XVI. Para la pérdida de las casas consúltese AzconA, Tarsicio de (O.F.M. CAP.): Isabel la Católica, Madrid, Editorial Católica, 1986, p. 94. La evolución y los usos del edificio pueden seguirse en AgAPITO y ReviLLA, Juan: Las calles de Valladolid, p. 67.

10. Contreras Jiménez, M. ${ }^{a}$ Eugenia: LLas fortalezas del Obispo de Segovia: Turégano y Lagunillas», Castillos de España, 95 (1988), pp. 59-66.

11. BeRnÁldeZ, Andrés: Historia de los Reyes Católicos don Fernando y doña Isabel, Sevilla, Imprenta que fue de José María Geofrín, 1870, cap. CLI, Esforza asesinó al duque de Gandía, hijo del mencionado Papa. ARAM, op. cit., p. 44 aporta este dato biográfico de don Juan.

12. He utilizado esta transcripción del testamento por la tradición historiográfica que tiene LE FLEM, Jean-Paul: 
que no dispongamos del acuerdo establecido para reedificar la ermita impide que sepamos cómo el comitente quiso gestionar su memoria en la edificación ${ }^{13}$.

En las últimas voluntades del obispo el heredero de sus bienes, Pedrarias de Ávila, quedaba obligado a repatriar los restos mortales de su tío en los dos siguientes años ${ }^{14}$.

Estas líneas muy generales de la interesantísima biografía del obispo segoviano hacen suponer que, entre I474 y I490, se situaron los momentos en los que el prelado, con mucha vinculación con Valladolid por su cargo en la Audiencia, toma contacto con la cofradía de los Santos Cosme y Damián. La relación de don Juan con la cofradía vallisoletana supuso el establecimiento de una nueva seña de identidad para el linaje Arias Dávila.

\section{DE PEDRO ARIAS DE ÁVILA, HEREDERO DE SU TÍO DON JUAN ARIAS DE ÁVILA, A PEDRARIAS, GOBERNADOR EN AMÉRICA: 1499 A 1531}

La herencia recibida por Pedro Arias originó una nueva Casa en la rama masculina de los Arias Dávila que debía organizarse para conseguir el reconocimiento de su posición en el conjunto de la parentela y en la sociedad en general. Pedro buscó que se enalteciese al obispo como estrategia de exaltación del origen económico de su propia estirpe, proveniente, así, de un antepasado «de buena memoria». Asimismo, engendró un amplio número de hijos legítimos en su matrimonio con doña Isabel de Bobadilla, asegurando que la herencia quedase en sus descendientes y no fuese aplicada al hospital que su tío había fundado ${ }^{15}$.

\section{II.1. PEDRO ARIAS DE ÁVILA Y LA MEMORIA DEL OBISPO EN VALLADOLID (1499 A 1511)}

El día I6 de julio de 1499 Pedro Arias de Ávila firmó con la cofradía de los Mártires un acuerdo. De esa manera la cantidad de dinero destinada a terminar la

\footnotetext{
«La première version castillane du testament de don Juan Arias Dávila, évêque de Segovie», Estudios Segovianos, XXII (1970), pp. 17-46.p. 41). La advocación de los Mártires tampoco se celebraba en Segovia de manera especial, ya que no figura entre las fiestas de precepto del obispado, como puede verse en Synodicon Hispanum VI, Antonio GARCíA Y García (dir.), Madrid, B.A.C., 1993, p. 487, sínodo de Segovia de 1478, título 7.

13. No se puede olvidar que los templos en una vía de comunicación con notable tránsito, como, por ejemplo, el humilladero del Cristo de la Luz en la ciudad de Ávila o los posteriores del Cristo de la Cruz de Valladolid o de la Virgen del Camino de Arévalo, partían de una realidad piadosa, pero conllevaban un fuerte elemento de propaganda para quien encargaba la obra.

14. LE FLEM, Jean-Paul, op. cit., pp. 35 y 42-3. Si el heredero no trajese los restos en ese plazo, perdería la heredad de Bernuy que pasaría a engrosar las propiedades del segoviano hospital de San Antonio, fundado por el padre del prelado, Diego Arias de Ávila. Bernuy de Palacios fue una aldea de Segovia situada junto al lugar de Madrona.

15. Le Flem, Jean-Paul, op. cit., p. 43.
} 
construcción de la ermita se iba a aplicar al hospital que atendía la hermandad, quedando obligados los cofrades a poner en él las armas del obispo y a decir una misa cantada y otra rezada por su ánima. El preconcierto se había establecido ya el 22 de abril: Pedro entregaría 320.000 maravedíes y serían celebradas misas por el alma de don Juan el día de los santos mártires, el primer domingo de cada mes y cuando se reuniese formalmente la cofradía ${ }^{\mathrm{i} 6}$.

El instrumento aporta otros matices ${ }^{17}$. Una importante representación de la cofradía de los santos Cosme y Damián aprobó en Valladolid, efectivamente, en julio un acuerdo establecido en abril entre algunos cofrades y Pedro; en él se fijó como causa de la variación que, aunque el obispo mandó finalizar la obra de ampliación «en la yglesia y hermitorio que es fuera de esta noble villa de Balladolyd en la vocaçión de los dichos bienaventurados... a (la a va escrita sobre una y) donde su señoría mando hacer la dicha iglesia», el templo no tenía necesidad de mayor superficie ni la cofradía disponía de recursos para sostener ni reparar un edificio mayor. Se adujo igualmente que los pilares de los arcos que el obispo ordenó hacer en la iglesia «como días ha que se hiçieron y an estado a las aguas e vientos descubiertos, están todos molidos y la obra que sobre ellos se fiçiere no sería duradera». Ante el buen estado de iglesia y eremitorio, convenía atender a que

tenían mucha gran neçessidad de reparar cosas tocantes al serviçio de Dios y de los bienaventurados sanctos Mártires, expeçialmente en fazer y hedifficar el espital que tiene la dicha coffradía dentro de esta dicha villa adonde se albergan y recoxen los pobres, y adonde los dichos cofrades se ayuntan a fazer sus cabildos y congregaciones y se juntan para dezir muchas misas y para otras cosas tocantes al serviçio de Dios y al bien y hutilidad y provecho de la dicha coffradía ${ }^{18}$.

Así pues, en 1499 se determinó lo siguiente:

16. Aram, Bethany: op. cit., pp. 45-46. Alcocer y Martínez, Manuel: «El Rosarillo», p. 35 y El Rosarillo. Estudio..., p. 7 y Agapito y RevilLa, Juan: Las calles de Valladolid. Nomenclator histórico (1937), Valladolid, 1937, facsímil 1982, p. 389, escribieron que la cofradía cedió la ermita a los monjes de San Basilio en Valladolid en 1499 porque a éstos se les había arruinado la iglesia. Sin embargo, Fernández del Hoyo, M. ${ }^{2}$ de los Ángeles: Conventos desaparecidos de Valladolid: patrimonio perdido, Ayuntamiento de Valladolid, 1998, p. 422 afirma que la ocupación del templo por esta orden se produjo en 1602 .

17. Archivo de los Condes de Puñonrostro (ACPU), sección Puñonrostro (PU), 61-24 a, 1499, julio, 16. Valladolid. El listado de cofrades es el siguiente: ese día el llamador era Juan de Michano y los cofrades presentes Juan González, lencero, alcalde; Luis Granada, alcalde; Pedro de Mucientes y Juan de Valladolid, mayordomos; Andrés de Olivares y Castilla, pintor, mayordomos de la obra; el doctor de Orduña; el provisor de Torquemada; Gómez García de Córdoba; Diego de Castronuño; Francisco de Paredes; Alonso de la Sierra; «lacome della La, escrivano»; Pedro de Atienza; García de León, «ozero»; Andrés López Torriero; Andrés González, cerero; Martín del Agua; Fernán García Binagroso; Albar García, armero; Juan de Valladolid, «mercadero»; Fernando de Ávila; Diego de Zamora, escribano; Juan de Collantes; Pedro Martínez, maestro de Roa; Gómez de Villalón; Juan de Oñate, platero; Juan de Segovia; Rodrigo de Palenzuela; Cristóbal de Eneina; Fernando de Valladolid, cambiador; Francisco Alonso, borceguinero; Antonio, pastelero; Pedro de Valladolid, yerno de Juan Ochoa; Diego de Mucientes; Francisco González, «mercadero»; Alonso, tundidor; Bernal, boticario; Hernando de Verdesoto; Fernando de Mucientes; Gonzalo Pérez; Guillen Martín, bule (sic); Fernando González, cabestrero; Pareja, barbero; Bartolomé de Mucientes; Fernando González, pintor; Pedro Sánchez; Alonso Delgado, linero; Rodrigo Herrera; Alonso Manchón, jubetero; Diego de Sevilla, jubetero; Francisco de Astudillo, platero; Bartolomé Sánchez; Xiralte, entallador; Diego Basurto, latonero; Bartolomé de Soria, mercader; Cristóbal, tundidor. Se menciona asimismo a los otros cofrades, clérigos y legos, ausentes. Como se puede ver, es una cofradía en la que se integran trabajadores del sector terciario y sólo en un caso se especifica que es boticario, oficio directamente relacionado con la advocación de los santos mártires.

18. ACP, PU, 61-24a, 1499, julio, 16. Valladolid. En el texto apenas se menciona Segovia, origen físico del linaje. 
$\mathrm{I}^{\mathrm{o}}$ : Los cofrades a su costa solicitarían del Pontífice una dispensa y licencia de permuta de la obra con poder de Pedro Arias, haciéndose la petición en nombre de ambas partes.

$2^{\circ}$ : Pedro, obtenida la licencia, abonaría a la cofradía como ayuda para erigir el hospital 320.000 maravedíes, tasación estimada por unos pedreros y carpinteros sobre la obra que el obispo quiso hacer. Los pagos serían de 50.000 anuales, situados en sus molinos de Buenaventura en la ribera del río Adaja, a una legua de Olmedo, y en los que tenía en la ciudad de Segovia ${ }^{19}$. Igualmente, correría con los gastos de la persona que fuere a recogerlos.

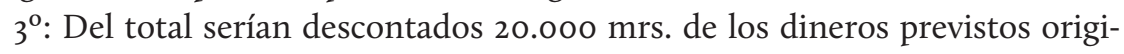
nalmente. Correspondían a una cantidad idéntica que Diego de Castronuño había dado para la obra y objetos ornamentales del hospital. Pedro Arias, además, entregaría para la edificación del dicho hospital roo cargos de madera según se acostumbraban a dar en Segovia, puestos en Valladolid a su costa, restándose por cada uno 80 mrs. La piedra utilizada en los cimientos y pilares de la ermita, según quiso don Juan, sería llevada y puesta en el edificio del hospital, no descontándose este traslado.

$4^{\mathrm{o}}$ : Los cofrades se obligaron por ellos y por sus sucesores a levantar el hospital a medida que percibieran las cantidades de dinero, tanto el edificio como una capilla «muy honrrada y su dormitorio y camas para los pobres y las otras offeçinas que se fueren neçessarias en el dicho hospital para recoxer y albergar en él los dichos pobres». Como reconocimiento al benefactor, en la capilla y en todas las partes públicas del hospital que fuesen labradas con estos dineros, se dispondrían las armas del obispo

para que sea memoria para siempre de cómo su señoría hedificó todo aquello y que no pongan otras armas en la dicha capilla e lugares públicos del dicho hospital sino las del dicho señor obispo, lo qual se obligan los dichos cofrades de lo guardar y complir por ellos y sus suszesores ${ }^{20}$.

$5^{\circ}$ : Los cofrades quedaban obligados «a poner por capítulo en su regla» que perpetuamente harían celebrar una misa de réquiem por todos los bienhechores

19. Álvarez Rubiano, Pablo: Pedrarias Dávila. Contribución al estudio de la figura del «gran justador», Gobernador de Castilla del Oro y Nicaragua, Madrid, C.S.I.C., 1944, pp. 711-4, en la enumeración de los bienes heredados, que se relacionan en el testamento de Pedrarias de 1514, figuran los molinos de Buenaventura con sus términos, alamedas y demás pertenencias y mejoras; siguiendo el testamento del obispo, eran los únicos dominios que se podían enajenar, cambiándoles por otros bienes raíces que se incorporarían a los ya vinculados.

20. ACP, PU, 61-24 a, 1499, julio, 16. Valladolid. Contreras JimÉnez, M. ${ }^{a}$ Eugenia, Linaje y transición histórica, pp. 361-379. Es preciso recordar que el emblema heráldico de los Arias fue descrito en el mayorazgo que otorgaron Diego Arias y Elvira González en 1462 como:

un escudo figurado en tres partes en esta manera: en la parte de arriba, a la mano derecha, una cruz gueca colorada en campo blanco; en la parte de la mano esquierda, un águila en canpo blanco; en la parte devaxo un castillo blanco en la puerta dél un arco turquesado, e todo el campo verde. E el dicho escudo es colorado con orleadura prieta en todo el derredor dél.

Tal y como ocurre en otros linajes de la época, los lugares donde se dispusieron dichas armas son muy variados, desde sepulcros y túmulos, a obras arquitectónicas, ajuar litúrgico, libros o reposteros. 
de la cofradía y hospital y nombradamente por el obispo, siendo cantada solemnemente «otro día de los bienaventurados Mártires». La no asistencia con el cirio correspondiente acarrearía unas penas no especificadas. Desde el comienzo de la misa estaría dispuesta una tumba según se requería para prelado, con un paño y con el escudo de don Juan Arias de Ávila -que debería donar Pedro Arias a su voluntad-; a continuación, el sacerdote celebrante rezaría un responso cantado con su oración.

$6^{0}$ : Otra de las obligaciones para todos los cofrades era la asistencia a una misa en el primer domingo de cada mes, en la cual se encomendaría a la totalidad de los bienhechores de la cofradía y hospital, y especialmente al alma del prelado. Asimismo, se estableció que, al finalizar, se rezaría un responso cantado sobre la tumba del obispo.

$7^{\circ}$ : Los cofrades igualmente incluyeron en su normativa y juraron por sí y por sus sucesores que todas las veces que se reunieran para rezar sus horas un clérigo haría una conmemoración de don Juan y de cómo él ordenó edificar el hospital. El sacerdote y todos los otros clérigos presentes dirían un responso con su oración y los cofrades rezarían «sendos Paternostres con sendas Avemarías» por el alma del prelado ${ }^{21}$.

$8^{\circ}$ : Los cofrades se obligaron a que con los maravedíes que restaran, después de edificado el hospital, adquiridos los ornamentos para la capilla y las camas que fueran necesarias para los pobres, comprarían algún censo u otra renta con la que se pudiera dar limosna a los necesitados que acudieran allí.

$9^{\circ}$ : Si pasados tres años desde la fecha del acuerdo los cofrades no hubieran traído la bula y licencia del Papa, Pedro Arias gastaría los dineros y la madera a su voluntad, siguiendo la disposición testamentaria de don Juan y sin impedimento.

$\mathrm{IO}^{\circ}$ : Pedro Arias se obligó a cumplir el contrato, bajo la pena de abonar el doble, con sus bienes y los de sus herederos, dando todo su poder a las justicias. Una vez abonado todo, los cofrades darían por libre a Pedro Arias, al ejecutor y al albacea del obispo de todo el derecho que tenían por virtud del testamento del prelado y se obligaron ellos mismos y sus sucesores a no solicitar otras cantidades, para lo cual pusieron como seguro los bienes espirituales y temporales de su casa ${ }^{22}$. Esta

21. Además de ser las oraciones propias de los cristianos, no se puede por menos que recordar las mandas de los testamentos de Pedrarias en las que ordenaba a su hijo mayor que rezase Avemarías en determinadas situaciones diarias, véase en Archivo Histórico Provincial de Segovia (AHPSg), protocolo 455, ante Juan de Zuazo, fol. 165, 1514, marzo, 20. Sanlúcar de Barrameda. Otras copias del testamento han sido publicadas por Álvarez RuBIANo, Pablo: op. cit., pp. 706-7 en especial, y MenA García, M. ${ }^{a}$ del Carmen: Un linaje de conversos en tierras americanas: (los testamentos de Pedrarias Dávila, Gobernador de Castilla del Oro y Nicaragua), Salamanca, Universidad de León, 2004, para la manda pp. 136-7; en esta última autora véase la transcripción del testamento de 1530 y esta orden en ibidem, pp. 165-166.

22. Fueron testigos Juan de Castroverde, Gómez de Portillo, Juan de Soto, Alonso Delgado, tejedor, y Francisco Banegas y Bartolomé, notario, vecinos de Valladolid. Dado que figuran sus nombres con un signo de separación entre ellos, se supone que estuvieron en el original las firmas de Pedro Arias de Ávila, de Francisco de Paredes, de Juan Núñez, del doctor Orduña y de Gómez de Córdoba.

Una vez leídos los contenidos de los capítulos, Pedrarias, el cabildo, alcaldes y mayordomos por sí y en nombre de los ausentes, dijeron que cumplirían lo acordado, razón por la que dieron todo su poder a las justicias de la Casa y Corte, 
cláusula es una expresión de cómo las cofradías estaban interesadas en dejar muy cerrados los acuerdos con particulares, no sólo para asegurarse de recibir todo lo estipulado como medio económico que permitía la continuidad, también porque demostraban la seriedad en el cumplimiento de acuerdos y esto podía atraer nuevos ingresos y donaciones ${ }^{23}$. El concierto establecido es, pues, una muestra de la fuerza que tenían en ese momento las cofradías dentro de la Iglesia, en cuanto a que se acudía a ellas como canalizadoras de una determinada expresión de religiosidad que conllevaba la gestión de los hospitales propios de cada una.

Tras este acuerdo, en I50o se documenta una compra que realizó la cofradía de San Cosme y San Damián «cuya bocaçión se celebra en su yglesia questá sytuada fuera de la puente del Río mayor de la dcha villa» ${ }^{24}$. En ella se hicieron con cierto suelo «çercado de tapias sobre sus çimientos de piedra e con su portada de piedra» que estaban en la plazuela de la Piñolería, en la parroquia de Santa María de la Antigua; parte de la superficie habían sido unas casas con su bodega, cubas, lagares y aparejos ${ }^{25}$, que heredó don Alonso Enríquez, deán de la Catedral de León, y descendiente del homónimo almirante de Castilla; el leonés las derribó dejando sólo «vna portada e su arco de piedra que sale a la Piñonería». Después de nuevos cambios de propiedad de esas casas y de otras colindantes, el día I de septiembre de I500 la cofradía de los Mártires abonó I35.000 mrs. por el espacio para erigir su hospital. La ceremonia de posesión tuvo lugar el 3 de octubre de ese año. Por fin el proyecto estaba en marcha.

Pedrarias fue realizando los pagos y así en Valladolid a i9 de marzo de I5II se otorgó un nuevo documento detallando los efectuados hasta ese momento y cómo, entregada la cantidad restante de 52.233 mrs., en piezas de oro y en reales de plata, se dio carta de pago y finiquito. Los cofrades reiteraron su obligación sempiterna $^{26}$. A partir de este momento las menciones siempre se hacen a la «confradía e ospital».

de la Chancillería, de Valladolid, de Segovia, y de otras ciudades y villas para que lo hicieran cumplir. He explicitado todo ello porque recordemos que Pedro Arias en ese momento está vinculado a Segovia porque allí está el origen y la sede principal de los bienes heredados, además de otras señas de identidad del linaje Arias Dávila.

Fueron otorgadas cartas para cada una de las partes ante Andrés Rodríguez de San Miguel, escribano de los reyes y del número de Valladolid.

23. Véase en este sentido el muy sugerente trabajo de Pérez González, Silvia M. ${ }^{a}$ : «Nuevas aportaciones al estudio de las cofradías y hermandades en la Castilla bajomedieval: el ejemplo de Jerez de la Frontera», Hispania Sacra, 138 (2016), pp. 503-520; en especial p. 515 sobre los aspectos económicos de los cultos.

24. Agapito y Revilla, Juan: «La Capilla Real de Valladolid», Boletín de la Sociedad Española de Excursiones, año LII (1944), segundo trimestre, pp. 115-144 e ibidem, tercer trimestre, pp. 161-203, véanse las páginas 181-188, apéndice 7. ARAm, Bethany, op. cit., pp. 45-46.

25. Según dicho documento, en 1467 pertenecieron a la cofradía de San Juan y San Mancio, que en 1500 fue fusionada a la de Santa María de Esgueva, de la O y de Todos los Santos.

26. ACP, PU 61-24C, 1511, marzo, 19. Valladolid, dentro en la dicha confradia e ospital de Sant Cosme e Sant Damian ante el escribano público Luis Alonso. Fueron testigos: Francisco de Cueto, el mozo, hijo de Francisco de Cueto, y Hernando de Aguilar, zapatero, vecinos de Valladolid, y además Juan Castro, vecino del lugar de Geria, jurisdicción de Valladolid, Cristóbal de Torres (el apellido está borroso, con tinta más suave y una corrección en la primera letra), criado del dicho escribano; éste último da fe de que conoce a los cofrades Bartolomé Sánchez, alcalde, y Pedro de Céspedes, mayordomo. Los diputados y algunos cofrades que firmaron la escritura ante los testigos en el registro fueron: Bartolomé 


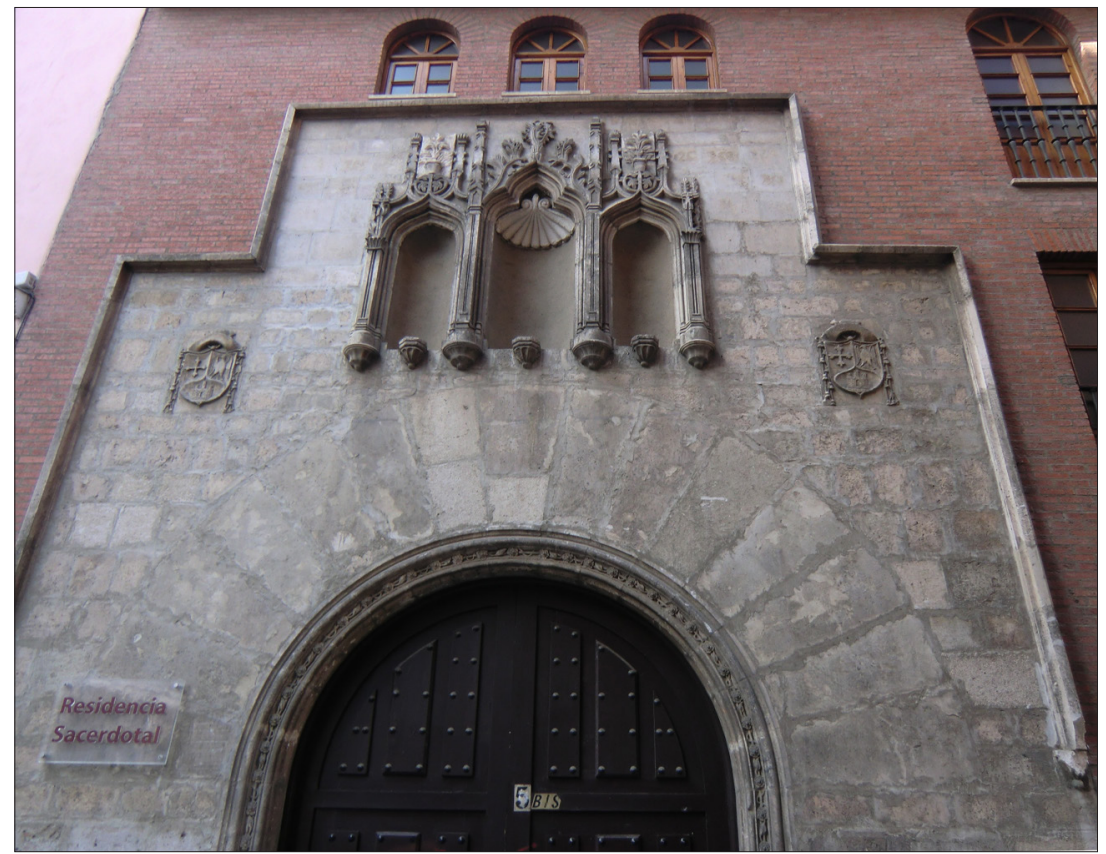

FOTO 1: LA FACHADA DEL HOSPITAL HA SIDO TRASLADADA HACE UNOS AÑOS PARA QUE SIRVIERA CON ESOS

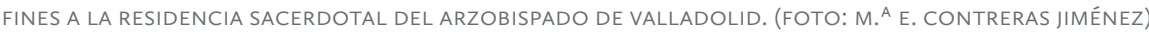

Se añade que:

- Pedro había entregado además una tumba de madera, un paño de seda de terciopelo negro doble de Génova de i 6 varas, forrado de bocarán, una alfombra y 10.000 mrs. de limosna para la cofradía ${ }^{27}$. Se vincula así a la fundación de su tío a través de donaciones propias realizadas en especie y en moneda, pero no en juros o en censos que implicaban una proyección en el tiempo de esas aportaciones. La inmediatez se une a que nada exigió a cambio. Cabe preguntarse si las dádivas fueron voluntarias o, por el contrario, resultado de un pago a mayores por haber demorado la liquidación de los 320.000 mrs. La documentación nada refleja en este sentido.

- Se había conseguido una bula del papa Alejandro VI, otorgada en Roma a II de abril de I499. Ahora bien, la licencia papal está fechada once días antes del

de Valladolid, Pedro de Céspedes, Juan de Madril (sic), Juan González, Pero Sánchez, pintor, Francisco de Aranda, Pe(continúa con tinte más clara y más apretada: dro de Montalvo), Bernaldino de Portillo, Bartolomé de Vitoria, Pedro de Mendiola, Rodrigo Alonso de Palençuela, Martín Juan de Valladolid Rubio, Juan de Segovia, Diego Giralte, Pedro de Cordoba, García de León, Sancho de Lacave, Diego de Esguevillas, Gómez de la Aya, Antonio de Postigo, Toribio de Valladolid, Fernand de Aguilar y Cristóbal de Torres.

27. Sobre el significado del color negro en cuanto a luto, magnificencia, humildad y autoridad, véase NogALES RINCÓN, David: «El color negro: luto y magnificencia en la Corona de Castilla (siglos XIII-XV)», Medievalismo, 26 (2016), pp. 221-245. 
primer acuerdo entre Pedro y la cofradía (22 de abril), hecho firme el i6 de julio y que incluía el viaje a Roma para solicitar el consentimiento. Como el texto del pontífice se dirige al noble Pedro Arias y a los integrantes de la cofradía instituida en la ermita de San Cosme y San Damián de Valladolid, dedicada a las necesidades de las personas en situación de pobreza, podría pensarse que la data del II pudiera ser tanto un error del copista como fruto de un acuerdo primero que hoy desconocemos. La sincera devoción, la íntegra fe y la abundancia de pobres y necesitados, son aducidas como razones de peso para que Alejandro VI diese la licencia de conmutación de la obra que sería aplicada «in constructionem et edificium novi hospitalis».

Así pues, en I5II la construcción es un espacio de memoria en la muerte ${ }^{28}$ : no es el lugar de inhumación del obispo, pero sí donde se hace una representación simbólica del mismo. Con todas sus acciones Pedro consiguió una remembranza de don Juan, origen de la nueva subrama familiar, así como del linaje representado en el emblema heráldico que hacía presente físicamente a los Arias Dávila a través de una de sus señas de identidad. ¿Qué sucedió para que el gobernador en América no se acordase de esta acción y de esta ermita en los testamentos de I5I4 y 1530 ? ¿Por qué se reavivó el recuerdo del hospital en el siglo XVII?

\section{II.2. PEDRO ARIAS DE ÁVILA Y LA MEMORIA DEL OBISPO EN SEGOVIA (1499-1506)}

Pedro Arias llevó a cabo en Segovia un proceso paralelo al anterior para honrar la memoria del tío que le dotó económicamente. El obispo don Juan Arias había ordenado en su testamento de I497

que las honrras y exequias el día de su muerte se celebren sin grande pompa y pocas hachas y que las limosnas sean grandes y copiosas y largas... y sea enterrado en la yglesia cathedral (sic) de la dicha ciudad [Segovia] entre los otros obispos sus predecesores pero que la piedra de encima de la sepoltura no sea más abaxada ni levantada o alta quel pavimento o empedramiento de la dicha yglesia ${ }^{29}$.

A pesar del espíritu de estas palabras, en 1499 su sobrino y heredero Pedro estableció con el cabildo de la Catedral de Segovia un acuerdo por el cual los canónigos, anual y perpetuamente, dirían por el alma del prelado en un día del ochavario de Todos los Santos una misa de prima cantada de réquiem capitularmente con preste, diácono y subdiácono en el altar del Crucifijo, que estaba en las espaldas del coro, donde don Juan quiso reposar eternamente. Otro compromiso fue el

28. DAcostA, Arsenio: «A propósito de un aparente silencio: la memoria genealógica escrita de la nobleza peninsular en la baja Edad Media», Tiempos modernos, 32 (2016/1), pp. 73-87, en especial pp. 76-77 considera elementos de la memoria linajística a la heráldica, onomástica, túmulos funerarios, textos genealógicos, etc., al igual que las casas principales en cada población eran la presencia física de la familia en la vida.

29. Le FLem, Jean-Paul, op. cit., pp. 34-5. 
rezo mensual de un responso solemne cantado sobre la sepultura ${ }^{30}$. Se conserva el testimonio de haberse celebrado el primero de ellos el día I4 de enero de $\mathrm{I}_{500}{ }^{3 \mathrm{I}}$. Dos años más tarde se añadió que durante la celebración de esta misa, se tendría que cubrir la dicha sepultura con una alfombra y encima una tumba revestida de un paño de terciopelo; igualmente, durante la misa arderían un par de hachas puestas por el mayordomo que llevase las pitanzas ${ }^{32}$.

Frente a las obligaciones del cabildo, Pedrarias tenía que dejar para la mesa capitular 7.00o mrs. de juro de heredad en el obispado de Segovia y por eso en I499 hipotecó sus derechos sobre las salinas de Córdoba. Por razones desconocidas, el día 3I de enero de 1503 fue prorrogado por dos años el plazo de cesión de aquella cantidad de maravedíes como dotación por las celebraciones litúrgicas conmemorativas ${ }^{33}$.

Pasado el tiempo, el día I4 de enero de 1506 Pedro Arias de Ávila, intitulado honrado caballero, como vecino de la ciudad, sobrino y heredero del obispo don $J_{u a n^{34}}$, modificó el acuerdo para que, cuando fuese rezado el responso mensual, se hiciera «tañer un clamor» y asperjar agua bendita sobre la sepultura. En relación con la misa en la octava de Todos los Santos, se determinó un completo ceremonial: en su víspera se diría una vigilia solemne «con sus caperos», nuevamente intervendría el sonido de las campanas y el agua bendita, y se dispondría un túmulo compuesto de un estrado cubierto por una rica alfombra, sobre él una tumba alta revestida con un paño de terciopelo que llegaría hasta el suelo y encima se ubicaría una mitra buena; se completaría la imagen situando delante de la tumba una cruz y alrededor cuatro hachas de cera encendidas, cada una de ellas de seis libras; en el altar, revestido en conformidad con lo demás, arderían cuatro velas; el diácono, subdiácono y dos mozos se vestirían con sus dalmáticas e incensarían durante el responso y vigilia. Al día siguiente, con la tumba y el

30. Liber consuetudinarius ecclesiae segobiensis in celebrandis horis canonicis et aliis, Archivo de la Catedral de Segovia (ACSg), B-428, fol. 9v, 1499, diciembre, 9. Fueron testigos Luis de Velliza, que había sido la mano derecha del obispo don Juan en asuntos seglares, el bachiller Francisco García Brunete, Antonio de Segovia y Antonio de Guadalupe, beneficiados de la Catedral. Los canónigos obligaron los bienes de la mesa capitular. Ante la presencia en ambos acuerdos de misas y responsos, así como de rezos de Padrenuestros y Avemarías cabe ver estas prácticas de devoción como las preferentes de la cristiandad en el paso del siglo XV al XVI.

31. En la memoria de difuntos del Liber consuetudinarius figura que se rezaba el día 3 de cada mes.

32. Liber consuetudinarius, fol. $9 v, 1502$, enero, 17.

33. Liber consuetudinarius, s.f., 1503, enero, 31. En esta ocasión los testigos fueron Juan Sedeño, mayordomo de la ciudad, Diego García de Robledo y Antonio de Peralta, «criado del dicho señor Pedrarias».

34. Liber consuetudinarius, s.f., 1506, enero, 14. Segovia; da la fe de esta escritura «que contiene toda la substancia del dicho acto», Diego de Guevara, notario público apostólico de la catedral de Segovia, sucesor de Alonso de Guevara. Guevara figuró como notario del número de la Catedral y audiencia episcopal de Segovia, y secretario del deán y cabildo. Estas ceremonias anuales contrastan con las del rey Enrique IV que en 1523 son descritas así en la transcripción de LeCEA y García, Carlos de: «Memorial histórico de Segovia, escrito por don Juan de Pantigoso en 1523», Boletín de la Real Academia de la Historia., XIV, (1889), pp. 212-261, véanse pp. 217-8:

Por el cual, demás de otros sacrificios que se hacen cada año, se dicen dos responsos muy solemnes con cantores y todos los beneficiados, puesto en estrado con dos tumbas, una sobre otra, ricamente adrezado, con su vulto cubierto con un rico paño de brocado, y encima una corona dorada, con sus armas reales alrededor: uno, víspera del señor San Frutos, y el otro víspera de la Concepción de nuestra Señora á las vísperas, en que su Alteza tuvo mucha devoción. 
altar así arreglados, las personas vestidas como se ha determinado y dispuesta una ofrenda de cuatro fanegas de trigo y cuatro cántaras de vino, se celebraría una misa de «requiem» cantada solemne; después se rezaría un responso solemne, incensando, haciendo un clamor y echando agua bendita sobre la sepultura. Todo se haría a costa del cabildo.

Pedro ofreció I.00o mrs. más, señalando como censo fetosín 80 fanegas de trigo anuales de la heredad que tenía en Bernuy de Palacios, aldea de Segovia junto a Madrona, con la obligación de situar antes de treinta años los 8.000 mrs. de juro en dicho obispado o de censo fetosín perpetuo en la ciudad o sus arrabales, esto a voluntad del cabildo. Ante el incumplimiento del acuerdo por parte de los canónigos, la mitad de los maravedíes o de las fanegas de pan de ese año se aplicarían a la fábrica de la catedral «por el mysmo hecho» y la otra mitad a Pedro Arias o a sus herederos para que con ello hiciesen cumplir las ceremonias. Por otra parte, si en los treinta años no fueran situados los 8.000 mrs., las 80 fanegas quedarían en la heredad de Bernuy de Palacios de censo perpetuo para la mesa capitular, pagándose en cualquier caso el día de San Bartolomé de agosto en dicho lugar ${ }^{35}$.

El concierto entre el cabildo y Pedrarias aflora en el testamento de 15I4, donde lega a su esposa, doña Isabel de Bobadilla, el usufructo de todos sus bienes bajo cumplimiento de determinadas condiciones, entre ellas, quitar las 80 fanegas de trigo anuales del censo que tenían el deán y cabildo de la catedral de Segovia sobre Bernuy de Palacios ${ }^{36}$. En I532, ya fallecido el Gobernador, las mencionadas fanegas seguían siendo para la Catedral ${ }^{37}$.

Así pues, Pedrarias utilizó los ritos e instrumentos de la memoria de la muerte para exaltar, con pretensiones de eternidad, al obispo en dos lugares, Valladolid y Segovia, y en dos ámbitos, el seglar y el eclesiástico; es decir, estableció hitos físicos como lugares de glorificación en la muerte del origen de su propia rama familiar. En Valladolid el recuerdo se establece sobre la voluntad de don Juan determinada en un momento que desconocemos y ratificada en su testamento, lo que puede justificar en parte la rememoración con una tumba en un lugar donde no reposan sus restos mortales. En Segovia, por el contrario, aunque el obispo había elegido un enterramiento discreto entre los prelados que le precedieron, Pedro determinó que se hiciera una remembranza de la muerte y de la vida de su tío, más concretamente, del cargo eclesiástico que don Juan ostentó hasta su

35. Si Pedro abonase la cantidad estipulada y los canónigos no se contentaran, ambas partes nombrarían sendos jueces para que se determinase si los dichos señores estaban obligados a recibir los maravedíes de juro o de censo, teniendo que acatar la decisión emitida; en caso de no llegar a un acuerdo, se acudiría como tercero al prior que hubiera en ese momento en el convento de Santa María del Parral de Segovia y lo que se determinara, obligaría a ambas partes. LE FLEM, Jean-Paul, op. cit., pp. 35 y 42-3, las fanegas estaban situadas sobre la heredad en Bernuy que el obispo legó a su heredero por repatriar sus restos a Segovia en dos años.

36. Álvarez Rubiano, Pablo, op. cit., p. 709.

37. ACSg, F-103, Noticias entresacadas de protocolos eclesiásticos, siglo XVIII, en 1532 doña Isabel de Bobadilla, ante Diego de Guevara, presentó una petición acerca de esta cantidad de grano. 
fallecimiento, a pesar del famoso proceso inquisitorial incoado contra sus padres y abuela materna.

El túmulo segoviano se elevaba sobre el suelo sosteniendo en su cúspide la mitra, convertido todo él en un símbolo de la fuerza del punto de partida de su Casa; en Valladolid la tumba mensual se limita a ser la apropiada para un obispo, si bien junto a ella se situaría una seña de identidad del linaje, el emblema heráldico. Otra diferencia radica en la cualidad de las donaciones: mientras la realizada para el hospital se efectuó en moneda y en especie, el grueso de las que percibió el cabildo era una renta en metálico, sustituida temporalmente por una entrega en especie. La razón de las divergencias posiblemente está en la localización de los restos mortales del obispo en Segovia; la tumba del personaje era un recordatorio continuo que merecía y exigía un pago con esperanza de perpetuidad ${ }^{38}$.

En ambos casos, buscó dar corporeidad a una proyección permanente del pasado hacia el presente, tal y como lo expresaron los corógrafos de la Edad Moderna.

\section{II.3. PEDRARIAS DÁVILA, GOBERNADOR EN AMÉRICA (1515-1531). LA EVOLUCIÓN DE SU PROPIA RAMA EN EL LINAJE}

Después de constituir y organizar los instrumentos de la memoria de don Juan, Pedro continuó una brillante carrera profesional que le llevó, tras importantes servicios a la Corona, a ser recompensado por ésta con dos mercedes de notoria importancia para el linaje Arias Dávila:

- El día I2 de agosto de I5I2 la reina Juana I le otorgó una modificación de su emblema heráldico. Las hazañas de este personaje en las guerras de Granada y, sobre todo, en la conquista de las plazas africanas de Orán y Bujía (I509 y I5IO) fueron la causa de la concesión de la merced ${ }^{39}$. A partir de este momento, tanto

38. Pérez González, Silvia M. ${ }^{\text {a }}$ op. cit., p. 518 escribe que las rentas fijas aseguraban la perpetuidad de los oficios por los difuntos.

39. Álvarez Rubiano, Pablo: op. cit., pp. 718-20. El relato de la toma de Bujía y la descripción de las nuevas armas es el siguiente:

en la toma de bugia en la cual entrastes por encima del muro con vuestra vandera e alguna parte de la gente de vuestra compañía . combatiéndo la dicha ciudad. donde matastes al alferes de los moros y le tomastes su uandera. E assí mismo ganastes el castillo de la dicha ciudad questá sobre el puerto de la mar e después teniéndole en guarda . vos vercaron grand muchedumbre de moros . y combatieron con tan grand resura desde casi ora de medio día hasta parte de la noche . estando vos con catorse ombres los nueve muy enfermos de pestilencia, y vos con los otros cinco defendistes el dicho castillo. Con tanta industria e ánimo que les tomastes siete escalas por do subían . los dichos moros . y en algun hemienda e remuneración dellos. E porque de vos. e de los dichos vuestros seruicios Aya perpetua memoria es mi merced e voluntad que vos e vuestros fijos que agora tenéis. O touiéredes de aqui adelante e sus descendientes para siempre jamás . podáis traer e traigáis por orla de vuestras armas antiguas la figura de la dha. vandera. y el dicho castillo y escalas que así ganastes . los quales es mi merced e voluntad que trayáis vos e los dichos vuestros fijos que agora tenéis e tuuiéredes e sus descendientes para siempre jamás dorados en testimonio de vuestra virtud . y en campo colorado que haga fee de la sgre (sangre) de los infieles que ende se derramó. E podáis faser e multiplicar . la figura del dicho castillo por la dicha orla . ocho 
él como sus sucesores portan en el emblema heráldico familiar una orladura con elementos que simbolizan la valiente participación en la toma de Bujía. La nueva identificación señala la propia rama de Pedrarias, diferenciándola de los demás Arias Dávila.

- El culmen de la carrera administrativa de Pedro fue su nombramiento el día 27 de julio de I5I3 como capitán general y gobernador de Castilla del Oro en el Nuevo Continente. Al día siguiente en Valladolid la reina le concedió licencia para especificar y declarar los bienes que le había dejado su tío el obispo don Juan Arias de Ávila ${ }^{40}$. Es la primera vez que aparece el término mayorazgo para definir el conjunto de aquéllos que legó el prelado, otorgándose, además, facultad para que el vínculo fuese engrosado con otros dominios que Pedrarias tuviese a bien o que pareciera en algún momento que fueron heredados de don Juan ${ }^{41}$.

Por tanto, I5I2 y I5I3 pueden ser considerados años decisivos en la formación de la propia Casa de Pedro dentro del linaje: la ramificación tomó cuerpo cuando se poseyó un emblema heráldico diferenciado y un mayorazgo que permitía una base económica importante y una estructuración familiar agnática.

En octubre de $15 \mathrm{I} 3$ el Gobernador ya estaba en Sevilla preparándose para su nuevo cargo transoceánico ${ }^{42}$. El tiempo fue pasando en América y Pedrarias, consciente de la necesidad de prolongación biológica de la subrama familiar establecida, comprendió que era necesaria la presencia de su hijo primogénito, Diego, en el origen físico de su Casa, Segovia. Así se concierta y lleva a cabo el matrimonio de Diego con doña Mencía de Ayala, de la toledana familia de los Rojas. De esa unión nacieron Pedro Arias de Ávila y Diego de Rojas.

Como es bien sabido, Pedrarias falleció en el Nuevo Continente el día 6 de marzo de $153 \mathrm{I}^{43}$. Es preciso reiterar que, a pesar del interés del Gobernador como cumplidor de la memoria y deseos de su tío don Juan, cuando testó nunca hizo referencia alguna a la cofradía o al hospital de San Cosme y San Damián de Valladolid, ni introdujo el nombre de los Mártires entre los santos a los que invocó, con lo que, según sus últimas voluntades, no correspondía ese culto a su devoción particular. Es más, ni siquiera deja una manda al hospital como hace con el de Benavente ${ }^{44}$. Puede aducirse que Pedrarias estaba dedicado al de la Anunciación, fundación de su tío el obispo, del que sí se preocupó y que estaba en Segovia,

veces porque en ocho oras que duró el dicho combate. En cada vna dellas fuistes jusgado de los xpianos E moros por muerto . y tomado el dicho castillo . la qual dicha orla de vuestras Armas sea en esta manera. 40. Álvarez Rubiano, Pablo: op. cit., pp. 710-1; el texto de este documento está inserto en el testamento de Pedrarias de 1514.

41. Álvarez Rubiano, Pablo: op. cit., pp. 711-4 para la enumeración de los bienes dentro del testamento de Pedrarias de 1514.

42. Mena García, M. ${ }^{a}$ del Carmen: op. cit., p. 54 y ss. El nombramiento fue conseguido por el patrocinio del obispo de Burgos, don Juan Rodríguez de Fonseca (presidente del Consejo de Indias y capellán mayor de Fernando de Aragón), del cardenal Cisneros y del propio Fernando de Aragón. Para la marcha ARAM 2008: 78-81.

43. ArAm, Bethany: op. cit., p. 410, comunicación de Fernando de Luque a doña Isabel de Bobadilla.

44. Mena García, M. ${ }^{2}$ del Carmen: op. cit., p. 165, manda 18; testamento otorgado en León (Nicaragua) a 23 de noviembre de 1530. 
junto a las casas principales en la parroquia de San Esteban, hoy integradas en el Palacio Episcopal de Segovia ${ }^{45}$.

Otro factor del desinterés pudiera estar relacionado con el hecho de que la cofradía ofreciera el patronazgo del hospital vallisoletano al almirante don Enrique Enríquez -que aceptó- el día 23 de octubre de I500, fecha muy cercana a la donación para erigir dicho hospital ${ }^{46}$.

\section{III.LOS MAYORAZGOS DE LA RAMA MASCULINA DE LOS ARIAS DÁVILA EN EL SIGLO XVI}

Si el siglo XVI había comenzado con la rama masculina de los Arias dividida en dos subramas, la finalización de la centuria trajo la fusión de ambas en una única, prevaleciendo aquélla que había conseguido el título nobiliario que les asentó definitivamente en altas posiciones sociales. La consecuencia fue la unificación y reorganización de focos de interés del linaje en todas las esferas.

En ambas Casas se aprecian rasgos comunes como la reducción de personajes adultos ${ }^{47}$ o como el descenso del prestigio socioeconómico familiar desde el primer conde de Puñonrostro y su hermano Pedrarias de Ávila.

\section{III.1. EL MAYORAZGO CONSTITUIDO CON LOS BIENES DEL OBISPO DON JUAN ARIAS DE ÁVILA}

Aunque esta parte de la familia sea la más desconocida, se pueden trazar unas líneas generales de cómo transcurrió su evolución a lo largo del XVI.

Tras el fallecimiento de Pedrarias, en I53I el mayorazgo pasó a su hijo Diego Arias. La toma de posesión de un regimiento en la ciudad del Acueducto en virtud de una provisión real a favor de Pedro Arias, hijo de Diego, en septiembre de I542, sugiere que quien fuera primogénito del gobernador en América había fallecido ya ${ }^{48}$.

45. Mena García, M. a del Carmen: op. cit., pp. 169-70, manda 52, testamento de 1530. El hospital de la Anunciación acabó fusionado al también segoviano de la Misericordia a mediados del siglo XVI.

46. Alcocer y Martínez, Manuel: «El Rosarillo», p. 36.

47. Para otros linajes castellanos se ha señalado como causa una baja tasa de natalidad, véase MONTERO TEJADA, Rosa M- ${ }^{a}$ : Nobleza y sociedad en Castilla: El linaje Manrique (siglos XIV-XVI), Madrid, Caja de Madrid, 1996, p. 96.

48. La presencia de Diego en los protocolos notariales es muy frecuente hasta 1529, sirva como ejemplo AHPSg, prot. 95 ante Pedro de Valera, fol. 132v, 1529, noviembre, 14. Segovia, corresponde a un documento otorgado por su mujer Mencía de Ayala, en el cual Diego figura como vecino y regidor de Segovia. Ibidem, fol. 193r, 1528, abril, 23. Segovia, sólo se presenta como vecino de esa ciudad. Ibidem, fol. 139 v, 1529, diciembre, 29. Segovia, añade entre sus cargos/ oficios la escribanía mayor de rentas de Córdoba y su obispado, que le tenía arrendado Ruy Pérez del Mijo, vecino de Córdoba, por 120.000 mrs. Para la toma de posesión véase Archivo Municipal de Segovia (AMSg), 1441-9, s. f. [s. XIX] recopilación de acuerdos de sesiones más antiguas. AHPSg, prot. 9870, ante Juan de Buisán, fol. 22, 1543, agosto, 14. Segovia menciona a doña Mencía de Ayala como la viuda de Diego Arias. 


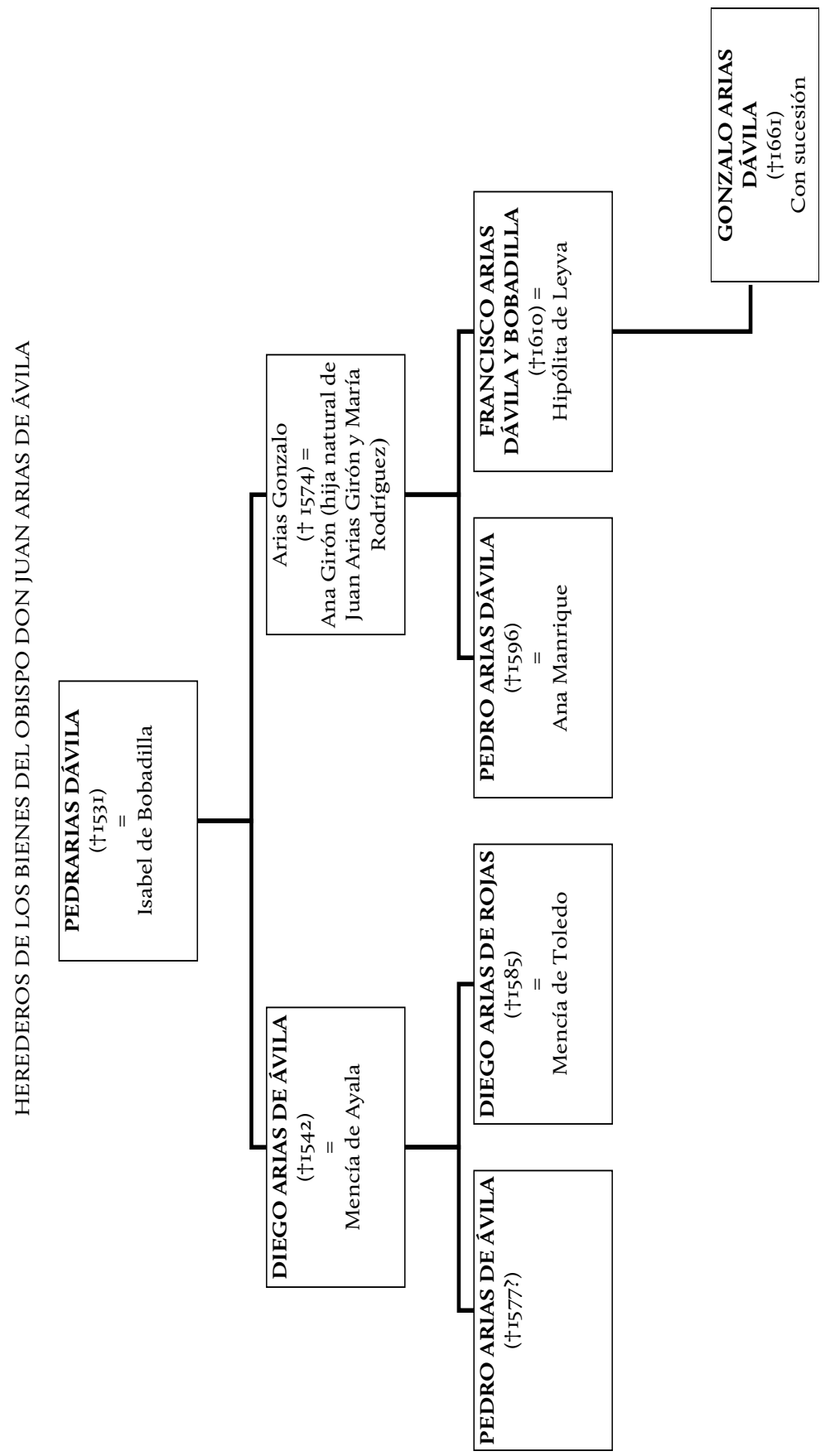




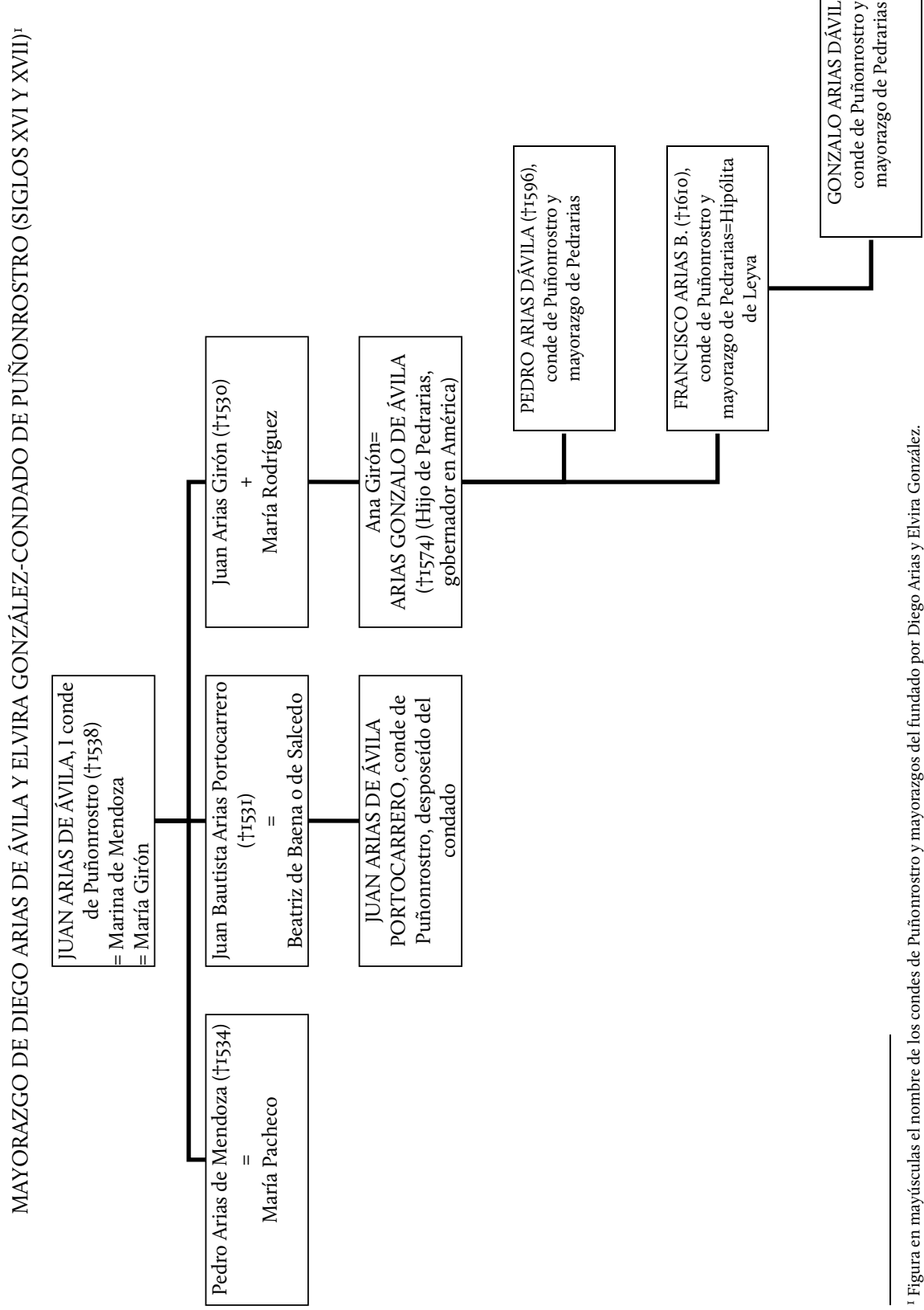


Más adelante, el día 2I de julio de 1562 Pedro Arias de Ávila, vecino de Segovia, otorga carta de poder a su hermano Diego de Rojas, estante en la corte real, para seguir

el pleito que yo trato con el obispo de Segovia sobre el patronadgo del ospital que llaman de la Anunçiaçión de Nuestra Señora, que dotó e fundó el obispo don Johan Arias Dávila, de buena memoria, obispo que fue en esta çibdad, mi señor, defunto, que santa gloria aya ${ }^{49}$.

Como se puede apreciar, Pedro Arias había asumido uno de los deseos de su antepasado y luchaba por mantener la institución que su abuelo homónimo, en calidad de primero de los herederos del prelado, puso en marcha o al menos en una cierta marcha. La final desaparición del establecimiento alejó una posibilidad que el obispo había previsto en su testamento: si su sobrino Pedrarias muriera sin hijo legítimo varón, todos los bienes raíces heredados serían aplicados al hospital que ordenaba fundar ${ }^{50}$.

En 1577 Pedro ya había pasado de esta vida sin descendencia y es su hermano, ahora llamado Diego Arias de Rojas al asumir el mayorazgo, quien está al frente de la Casa ${ }^{51}$. Y así será hasta octubre de 1585 en que, al fallecer sin hijos de su matrimonio con doña Mencía de Toledo, su mayorazgo es heredado por su primo Pedro Arias de Ávila, que llegó a ser conde de Puñonrostro ${ }^{52}$.

La reintegración de la rama principal de Pedrarias en el tronco del linaje Arias Dávila conllevaba un patrimonio físico e inmaterial que fue atendido con distinta solicitud en cuestiones tales como el mantenimiento de la memoria de los orígenes de los dos mayorazgos familiares.

\section{III.2. EL MAYORAZGO PRINCIPAL DE LOS ARIAS DÁVILA EN EL SIGLO XVI}

En este punto es necesario volver atrás en el tiempo, hasta el primer tercio del siglo XVI, para explicar el por qué de la fusión de las dos subramas que estamos considerando.

El primer conde, don Juan Arias, no tuvo nietos ni de su primogénito, Pedro Arias, ni de su favorito, Juan Arias Girón, pero sí de su otro hijo varón, Juan Bautista Arias de Portocarrero, con el que mantuvo continuos y duros enfrentamientos a lo

49. AHPSg, prot. 283, ante Marcos de Benavente, fol. 632, 1562, julio, 21. Segovia; el poder se extiende a todos mis pleitos. Ya el año anterior se documenta la mención al muy magnífico cavallero Pedrarias Dávila, sobrino del dicho obispo don Joan Arias Dávila y heredero universal de Pedrarias Dávila, su aguelo, heredero universal que fue del mesmo obispo, en AMSg, Leg. 345-4, 1561, mayo, 31. Valladolid.

50. LE FLEM, Jean-Paul, op. cit., p. 43 para la transcripción de las últimas voluntades.

51. AHPSg, prot. 289, ante Luis González Varillas, fols. 231-2, 1577, marzo, 5. Segovia.

52. AHPSg, prot. 8111, ante Juan Martínez, fol. 350, 1585, octubre, 27. Juarros de Voltoya (Segovia). Es un mandamiento para la toma de posesión de tierras y bienes del mayorazgo que poseyó Diego Arias de Rojas, por parte de su heredero don Pedro Arias de Ávila. 
largo de su vida. La situación llegó a tal punto que el Conde se negó a reconocer el matrimonio de Juan Bautista y el fruto de él, don Juan Arias Dávila Portocarrero; por eso planificó y determinó el casamiento en I530 de una nieta suya, Ana Girón, hija bastarda de su preferido Arias Girón, con Arias Gonzalo Dávila, hijo vivo segundón y soltero de su hermano el gobernador en América. El conde, con un claro sentido del linaje y asumiendo su papel de pariente mayor en el mismo, buscó dentro de sus sobrinos, hijos de su hermano segundón -y no olvidemos organizador de una nueva subrama- la posibilidad de la unificación de la rama masculina de los Arias. De esta manera, el cuarto hijo varón de Pedrarias, Arias Gonzalo, fue protagonista decisivo en la evolución del condado de Puñonrostro.

Las luchas por conseguir el mencionado condado supusieron costosísimos pleitos a lo largo del reinado de Felipe Il. Al final, don Juan Arias Dávila Portocarrero (hijo de Juan Bautista Arias y, por tanto, nieto del primer conde) fue desposeído del mismo. El título condal y el mayorazgo recayeron de forma definitiva desde I588 en nietos de Pedrarias, gobernador en América, hijos de Arias Gonzalo y de Ana Girón: primero en don Pedro Arias de Ávila, ya mencionado por heredar el mayorazgo del obispo, y luego en su hermano, don Francisco Arias de Bobadilla ${ }^{53}$.

Esta cuestión explica que a partir de entonces los emblemas heráldicos de los condes de Puñonrostro muestren la orladura concedida a Pedrarias por Juana I.

Así las cosas, en la segunda mitad del siglo XVI descendientes de Pedrarias fueron la cabeza de los dos mayorazgos de la rama masculina de los Arias Dávila: el fundado en 1462 por el contador Diego Arias y el constituido en I5I3 con los bienes legados en 1497 por don Juan Arias, obispo de Segovia; en definitiva, el conseguido por diversas circunstancias y el heredado por vía directa, respectivamente.

\section{DON FRANCCISCO ARIAS DÁVILA Y BOBADILLA, CONDE DE PUÑONROSTRO (NOVIEMBRE DE 1596 - ENERO DE 1610) Y MAYORAZGO DE LOS BIENES VINCULADOS HEREDADOS DEL OBISPO DON JUAN ARIAS DÁVILA: 1607}

Tras la toma definitiva de posesión del condado de Puñonrostro por don Pedro Arias Dávila en 1588, una nueva ausencia de hijos en el matrimonio de este personaje con doña Ana Manrique provocó que la sucesión recayese en su hermano don Francisco Arias de Ávila y Bobadilla en I59654.

Don Francisco fue un destacado militar que participó en diversas empresas bélicas de la Monarquía Hispánica en el resto de Europa y por designación real desempeñó

53. Sobre las aventuras y desventuras de Juan Bautista Arias de Ávila y sus descendientes de sangre véase MARTín OrtegA, Alejandro: Historia de la villa de San Agustín, Madrid, 1954, capítulos VII, VIII y IX, pp. 199-248.

54. Martín Ortega, Alejandro: op. cit., pp. 251-2 y 255. 
los cargos/oficios de asistente y caballero veinticuatro en Sevilla, así como perteneció al Consejo de Guerra55. El mismo año que recibió el condado de Puñonrostro, 1596, contrajo matrimonio con doña Hipólita de Leiva Cardona, hija del virrey de Navarra entre 1575 y 1579 Sancho Martínez de Leyva y de su segunda esposa Hipólita Eril de Cardona, hija a su vez del barón de Albi. El matrimonio, muy tardío para el Conde, consiguió la proyección biológica imprescindible para la continuidad del linaje en su hijo don Gonzalo Arias de Ávila.

Una de las facetas de la vida de don Francisco que ha llamado la atención a los historiadores, ha sido la del enfrentamiento que mantuvo en los primeros años del siglo XVII con el cronista Antonio de Herrera por el texto redactado sobre Pedrarias Dávila, el gobernador en América, que se iba a publicar en una de sus obras principales $^{56}$. Don Francisco fue el gran defensor de la figura de su abuelo, que era, repito, el origen biológico masculino de los dos mayorazgos que ostentaba aquél. Una de las razones de la dicha defensa pudo ser que don Francisco y Pedrarias fueron ambos hombres de armas y de servicio a la Corona fuera y dentro del territorio peninsular, ya que existe una cierta tendencia a exaltar a aquél antepasado de características más similares a la propia vida. Además, en un momento en el que la Historia es vista como una proposición de modelos del pasado para los hombres del presente, la imagen negativa de Pedrarias tuvo que ser vista como una afrenta al linaje por la negatividad que suponía, dado que una mancha en un individuo afectaba negativamente a la memoria histórica externa del grupo familiar.

Empero las similitudes con la figura de su abuelo no acaban aquí, puesto que, al igual que aquél, incrementó el vínculo con Valladolid.

Los comienzos del siglo XVII habían traído, es bien sabido, cambios en la corte real, que fue situada allí durante un breve periodo de tiempo (I60I-I6o6)57. El traslado supuso que una de sus cofradías, bajo la advocación de Nuestra Señora del Rosario, se quedase sin parte de sus instalaciones ante el interés que, ya desde la centuria anterior, tuvieron las reinas de la Monarquía Hispánica en tomar como suya la capilla del Rosario. El atractivo era debido a la cercanía del templo a un edificio en que se aposentaban.

55. Martín Ortega, Alejandro: op. cit., pp. 255-257. El interés de la figura de este personaje ha hecho que en 2012 M. J. Fernández Rodríguez presentase una tesis doctoral sobre él en la universidad de Sevilla, bajo el título de Francisco Arias de Bobadilla, conde de Puñonrostro. Asistente de Sevilla (1597-1599).

56. Véase Martínez Martínez, M. ${ }^{a}$ del Carmen: «Pro defensione veritatis: Antonio de Herrera, Cronista Mayor de Indias », e-Spania [En ligne], 18 | juin 2014, mis en ligne le 26 février 2018; consultado el día 24 de abril de 2019 por última vez. URL: <http://journals.openedition.org/e-spania/23687>; <DOI: 10.4000/e-spania.23687>.

57. Acerca de Valladolid cabe destacar las obras de Gutiérrez Alonso, Adriano, Martín González, Juan José, URrea, Jesús, Rubio González, Lorenzo, VIRGILI BLANQuet, M. a Antonia: Valladolid en el siglo XVII, Historia de Valladolid, IV, Valladolid, Ateneo de Valladolid, 1982, así como GutiÉrRez Alonso, Adriano: Estudio sobre la decadencia de Castilla. La ciudad de Valladolid en el siglo XVII, Valladolid, Universidad de Valladolid, 1989, e ibidem, «El siglo XVII», Historia de Valladolid, Valdeón BARUQUe, Julio (ed.), Valladolid, Ámbito, 1997, pp. 131-154; igualmente, se puede consultar el tomo II de Valladolid. Historia de una ciudad: congreso internacional: II, Valladolid, Ayuntamiento de Valladolid, [1999] y el artículo de ENCISO RECIO, Luis Miguel: «Apuntes sobre religiosidad y secularización de costumbres en Valladolid a comienzos del siglo XVII», en Estudios en homenaje al profesor Teófanes Egido, Sobaler SeCo, M. a de los Ángeles y García Fernández, Manuel (coords.), II, Valladolid, Junta de Castilla y León, 2004, pp. 51-72. 
La mencionada cofradía había sido beneficiada en 1504 por doña Catalina del Corral que fundó y dotó un hospital y una sala de juntas, situados en la parroquia de San Miguel. En la institución habría ocho camas para que otras tantas viudas sin recursos que tuvieran que acudir a pleitear a Valladolid, contasen con un lugar de apoyo donde se las cuidaría en caso de enfermar y se las inhumaría, si fuese necesario. En 552 parece ser que acogía a veinte pobres ${ }^{58}$.

Tras la real intervención en la capilla del dicho hospital, se produjo la fusión con la cofradía de San Cosme y San Damián, cuya iglesia y hospital en la plazuela de la Piñolería, parroquia de Santa María de la Antigua, quedaron como los edificios señeros. Se llevó a cabo la unión el 28 de octubre de 1602 y se celebraron unas fiestas que fueron dirigidas por el licenciado Gregorio de Camargo, cofrade del Rosario ${ }^{59}$. En la séptima cláusula del documento de unificación se dice que, dado que los pobres auxiliados en los Mártires eran hombres mendigos recogidos de noche y que el Rosario protegía mujeres honradas, serían éstas las que se quedarían en el hospital con doce camas y los menesterosos tendrían que acogerse en otros hospitales de la ciudad ${ }^{60}$.

El texto hace pensar que el Rosario impuso muchas condiciones, pero lo que tenían asumido ambas es que debían seguir cumpliendo por siempre con «todas las memorias, procesiones, fiestas que las dichas cofradías que hasta agora an echo y se ayan de hacer y ayan de aquí adelante, todas ellas, aunque no conste de su fundación ni doctación, ni se sepa de su principio» ${ }^{61}$. En ello iba su credibilidad presente y futura.

Otra de las disposiciones informa de que la unión tendría efecto a partir de que

los niños de la capilla del Rey nuestro Señor e sus capellanes e Ministros se vayan a vivir fuera deste hospital [de los Santos] y le dexen libre e desembarazado, questando ellos dentro no es posible el hacerse ni cumplirse lo contenido en esta unión e concierto ${ }^{62}$.

58. Agapito y Revilla, Juan: «La Capilla Real de Valladolid», pp. 117-131 y 174. Para las primeras cofradías bajo esta advocación véase Romero MensaQue, Carlos José: «Los comienzos del fenómeno rosariano en la España Moderna. La etapa fundacional (siglos XV-XVI)», Hispania sacra, LXVI (2014), Extra II, pp. 243-278. ACSg, F-115, (s.f.) [primera mitad del s. XVI], (s.I.), documenta que la cofradía del Rosario de Valladolid percibía cierta cantidad de maravedíes en un juro situado en las rentas de la ciudad de Segovia.

59. Agapito y Revilla, Juan: «La Capilla Real de Valladolid», pp. 135-136. Camargo fue un personaje de destacada actividad en la cofradía que mereció que en 1605 se le concediera un arco y sepultura en el hospital para su inhumación. El dato ha sido recogido por Anastasio Rojo de la Vega en

https://investigadoresrb.patrimonionacional.es/node/8909

consultado por última vez el día 29 de abril de 2019.

Para más actividades de Camargo en relación con el Colegio de Niñas Huérfanas de Valladolid, véase AgAPITO Y ReVILLA, Juan: Las calles de Valladolid..., p. 212.

Archivo de la Real Chancillería de Valladolid, Reales ejecutorias, caja 2511/71, 1628, diciembre, 16. Valladolid; en 1622 se dice que Camargo fue «capellán de Nuestra Señora del Rosario y Santos Mártires de Valladolid»; ya en 1621 había otorgado poder para gestionar unas obras pías, memorias y dotes de huérfanas que había dotado y fundado en Roa de Duero (Burgos).

6o. Agapito y ReVilla, Juan: «La Capilla Real de Valladolid», p. 178, apéndice 6.

61. Alcocer y Martínez, Manuel: El Rosarillo. Estudio..., X, cláusula 8; en las 9 y 10 se acuerda que se realizarán libros de obligaciones y cargas y de inventario de todos los bienes de ambas cofradías.

62. Alcocer y Martínez, Manuel: El Rosarillo. Estudio..., XII-XIII, cláusula 17; en ella se alude a que el principal 
En I607, por tanto, una vez que ya la corte había vuelto a Madrid, se inició sobre el 30 de junio una correspondencia entre el conde de Puñonrostro y el clérigo licenciado Gregorio de Camargo, vecino de Valladolid, que tuvo como resultado la donación por parte de don Francisco de una lámpara de plata para que alumbrase el Santísimo, situado en la capilla mayor de la iglesia y hospital de San Cosme y San Damián ${ }^{63}$. En la fe que firmó Alonso Requejo, contraste de la ciudad de Valladolid, se dice que había sido realizada por Toribio Asenjo de Estrada, platero, vecino de dicha ciudad, y había pesado ella, los aderezos de cadenas y la cobertera 26 marcos, 6 onzas y 3 ochavas, a ocho ducados el marco de plata, con lo que el coste total fue de 2.359 reales. La hechura se había llevado a cabo según el concierto entre Asenjo y Camargo, que actuó por comisión del Conde. Asenjo otorgó carta de pago, añadiendo que el clérigo «en mi presencia entregó a los alcaldes de la cofradía de San Cosmes (sic) y San Damián» la lámpara trabajada por él ${ }^{64}$.

El día 17 de septiembre de ese mismo año se celebró una reunión de la cofradía de Nuestra Señora del Rosario y Santos Mártires San Cosme y San Damián en su cabildo, en la sala de su casa especial ${ }^{65}$. Se había producido la convocatoria por parte del casero y llamador de dicha cofradía, Alonso Caballero, acudiendo alcaldes, diputado, mayordomos y otros cofrades ${ }^{66}$. En la reunión se leyeron las cartas dirigidas por Puñonrostro a Camargo en las que aquél pedía que la cofradía se obligase por ellos y sus sucesores a conservar la lámpara sin poder disponer de ella, cambiarla por otra que otro benefactor donase o modificar el lugar en que se iba a colocar: en medio de la capilla mayor de la iglesia, delante del altar mayor y de la custodia del Santísimo. Los cofrades aceptaron y recibieron la mencionada lámpara, comprometiéndose a lo que pedía el conde y a no cambiarla, aunque fuese donada otra de más notables cualidades. El cabildo acordó que fuera entregada al mayordomo de hacienda de la cofradía, ya que tenía a su cargo los bienes

\footnotetext{
motivo de la fusión estaba en el servicio a Dios, a la Virgen María y a los Mártires; se repite que se celebrasen las memorias y obligaciones de ambas cofradías.

63. ACP, PU 61-24d e ibidem, 61-24e, 1607, septiembre.

64. ACP, PU 61-24d, 1607, septiembre, 14. Valladolid.

65. ACP, PU 61-24e, 1607, septiembre, 17. Valladolid.

66. ACP, PU 61-24e, 1607, septiembre, 17. Valladolid; los presentes fueron García Ruiz y Jerónimo González, alcaldes de la cofradía, Gonzalo de la Concha, diputado, Pedro de Robles y Antonio de Salas Esplugas, mayordomos, el licenciado Gregorio de Camargo, el doctor Diego Enríquez de Salas, Luis de Benavides, Alonso de Godoy, Blas López Calderón, Rodrigo Manojo, Antonio Pérez y Juan del Moral; actuaron por sí y prestaron voz por los demás que estaban ausentes, enfermos e impedidos, y que por tiempo fueren en la dicha cofradía, palabras que sugieren una cierta prelación por antigüedad dentro de los cofrades. Como puede verse, no se alude en momento alguno al oficio de ninguno de ellos por lo que no parece una cofradía gremial como la que, con la advocación a los santos Mártires, se fundó en la parroquia de Santiago en 1578, compuesta por barberos, según LARRUGA, Eugenio: Memorias Políticas y económicas... de la ciudad de Valladolid, T. XXIII, En Madrid por Don Antonio Espinosa, Año MDCCXCII, fol. 117, n 56, obra que ha generado tradición bibliográfica en este tema; véase, por ejemplo, EGIDO, Teófanes: «Religiosidad popular y asistencia social en Valladolid: Las cofradías marianas del siglo XVI», Estudios marianos, 45 (1980), pp. 197-217. Sirva de muestra de oficios la figura de Gonzalo de la Concha, procurador de la Real Chancillería de Valladolid, según documentación de 1581 del Archivo Histórico Provincial de Zaragoza:

<http://aplicaciones.aragon.es/opac/app/item/?vm=nv\&p=0\&ft=place:Valladolid\&st=.2.6.100\&in=\%22Casa+Duc al + de + H\% $3 \%$ ADjar-Aranda\%22\&i=204011>

consultado por última vez en 27 de agosto de 2019.
} 
y rentas de ella ${ }^{67}$. La cercanía de la data de la reunión al 26 de septiembre, fecha en que la Iglesia conmemora a los hermanos mártires, pudiera hablar de un deseo de que estuviera colocada para lucirla desde ese día, si bien nada se explicita en este sentido.

La relevancia de la mencionada lámpara aumenta en el momento en que se lee su descripción. Estaba recercada con tres escudos de armas de don Francisco Arias de Ávila y Bobadilla, conde de Puñonrostro, y de su mujer doña Hipólita de Leyva Cardona, con un epígrafe alrededor del medio cerco donde se decía cómo el conde la donó y ofreció para que se pusiera en la capilla mayor de la iglesia y hospital para alumbrar al Santísimo. También se añadía el año de la donación, $1607^{68}$.

En la dádiva pudo haber devoción postrentina pero también propaganda, ya que la cofradía del Rosario tenía concedidas indulgencias en ese preciso altar ${ }^{69}$. En cualquier caso, la posición de la lámpara era ostentosa y portaba unos emblemas heráldicos que, en una sociedad que no sabía leer en su mayor parte, eran interpretados con gran claridad, de manera que generaban una presencia física que podía indicar una cierta propiedad sobre ese ámbito eclesiástico. Igualmente, la inscripción precisaba un personaje y un tiempo concreto, es decir, un eslabón definido dentro de la cadena que es el linaje. Así se generaba memoria personal dentro de un espacio que mostraba los emblemas heráldicos del antepasado, es decir, del linaje, como recordatorio constante.

En este caso, la introducción de los emblemas de doña Hipólita de Leyva junto a las propias de los Arias Dávila supone la plasmación de una alianza matrimonial con otra importante familia en el espectro nobiliar del reino. Además, ella fue la primera mujer generadora de un nuevo heredero en varios enlaces (Pedro Arias, su hermano Diego Arias de Rojas y don Pedro Arias, conde de Puñonrostro, murieron sin hijos legítimos), con lo que la continuidad biológica estaba asegurada. Quizá por eso fue representado su escudo junto al de los Arias en una cierta igualdad de posición. Por otro lado, es la única mujer Arias Dávila, aunque sea por matrimonio, que figura relacionada con la cofradía en la documentación conservada en el archivo nobiliar.

67. ACP, PU 61-24e, 1607, septiembre, 17. Valladolid; el escribano fue Blas López Calderón, escribano público, vecino de Valladolid; los testigos fueron Pedro Jorde, Alonso González y Pedia (sic) González, estantes en Valladolid. Firmaron Jerónimo González, Gregorio de Camargo, Gonzalo de la Concha, el doctor Diego Enríquez Salas, Alonso de Godoy, Luis de Benavides, Antonio de Salas Esplugas, Antonio Pérez, Rodrigo Manoxo, Juan de Moral y Pedro Jorde, como cofrades. Esta escritura quedó asentada en el libro nuevo de los cabildos de la cofradía que comenzó en 13 de diciembre de 1602 y, advierte el escritor, allí se hallará por si pudiera ser necesaria en algún tiempo, expresión que hace patente el deseo de justificar eternamente que supone la custodia de documentación en un archivo, según los intereses de quien lo conforma.

68. ACP, PU 61-24d, 1607, septiembre, 7. Valladolid.

69. Agapito y ReVilla, Juan: «La Capilla Real de Valladolid», p. 177, apéndice 6. El mencionado altar formaba parte del conjunto de aras que proporcionaba una buena inversión por las rentabilidades espirituales que suponía, en palabras de EGIDO, Teófanes: «Formas de religiosidad en la época moderna», Valladolid. Historia de una ciudad: congreso internacional, II, [Valladolid], Ayuntamiento de Valladolid, [1999], pp. 511-524, pp. 520-1. 
Con todo, la cofradía estaba iniciando una nueva etapa fusionada con la del Rosario. En la entrega de este objeto puede verse un deseo de hacer patente la presencia del linaje en la nueva institución.

Junto a lo anterior se advierte la consecuencia de la donación de don Francisco: se vuelve a hacer visible a los Arias Dávila en la cotidianeidad de la capilla, pero lejos queda la consideración de las necesidades de los menesterosos atendidos en el hospital al que pertenecía.

\section{DON GONZALO ARIAS DÁVILA, CONDE DE PUÑONROSTRO (1610- FEBRERO DE 1661) Y MAYORAZGO DE LOS BIENES HEREDADOS DEL OBISPO DON JUAN ARIAS DÁVILA: 1630}

Don Gonzalo heredó a su padre en minoría de edad, lo que llevó al condado a una situación de tutoría de la condesa madre, doña Hipólita, que orientó a su hijo hacia el servicio real.

En su etapa al frente de la Casa fueron variadas las señas de identidad del linaje Arias Dávila, ya que estableció en su testamento el deseo de ser enterrado en el convento de San Juan Evangelista de Trinitarios Descalzos de Torrejón de Velasco. En dicho convento su madre había fundado patronato en la capilla mayor a fin de convertirla en el nuevo panteón familiar de los condes de Puñonrostro ${ }^{70}$.

Al tiempo, se documenta en r630 el interés de la Casa de Puñonrostro por un edificio vinculado a la memoria de uno de sus antepasados ilustres, el hospital de San Cosme y San Damián en Valladolid. Así, el mayordomo del conde, Tomás Eugenio de Prado, acudió a la plazuela «que llaman de los Mártires en la Piñolería» acompañado del escribano Gregorio Herrero para que diera testimonio de cómo en la puerta principal del claustro e iglesia de Nuestra Señora del Rosario y Santos Mártires había encima de la puerta y a los lados de ella dos escudos de armas en piedra, uno a cada lado, y en medio unos nichos con unas esculturas de esa advocación de la Virgen entre las pertenecientes a San Cosme y a San Damián ${ }^{71}$. Invocando la guarda del derecho del linaje, Prado pidió que el escribano diera fe de la descripción de los emblemas heráldicos y del capelo con sus borlas que había encima de ellos, emblema que dicho mayordomo identificó como correspondiente al Conde y a sus antecesores. Efectivamente, el escribano levantó acta de toda la

70. Acerca de la fundación véase ACP, PU 51-15a, 1631, abril, 7. Madrid. Para estos personajes puede consultarse Martín OrtegA, Alejandro: op. cit., pp. 258-9.

71. La posición de las esculturas también merece un comentario dado que en la tercera condición de la escritura de fusión de las cofradías, otorgada como ya se vio, el 28 de octubre de 1602, se especifica que en todos los retablos y lugares donde se hiciera una representación plástica, siempre se pondría la imagen de la Virgen en medio y las correspondientes a los santos Mártires uno a cada lado de ella. Véase la cláusula en AGAPITO Y REVILLA, Juan: «La Capilla Real de Valladolid», p. 179, apéndice 6. 
mencionada disposición y descripción de elementos en la fachada e incluso se incorporó al documento un dibujo monocolor a mano alzada del escudo, con la firma del dicho escribano autenticándole ${ }^{72}$.

El contenido del escrito requiere alguna puntualización referida al emblema heráldico: en primer lugar, las borlas, en cuyo dibujo la imaginación voló bastante, y el capelo hacen que claramente las armas correspondan al obispo don Juan Arias, del cual no se hace ninguna mención, ya que a quien en el siglo XVII se identifica a través de los escudos de la fachada es al linaje del conde de

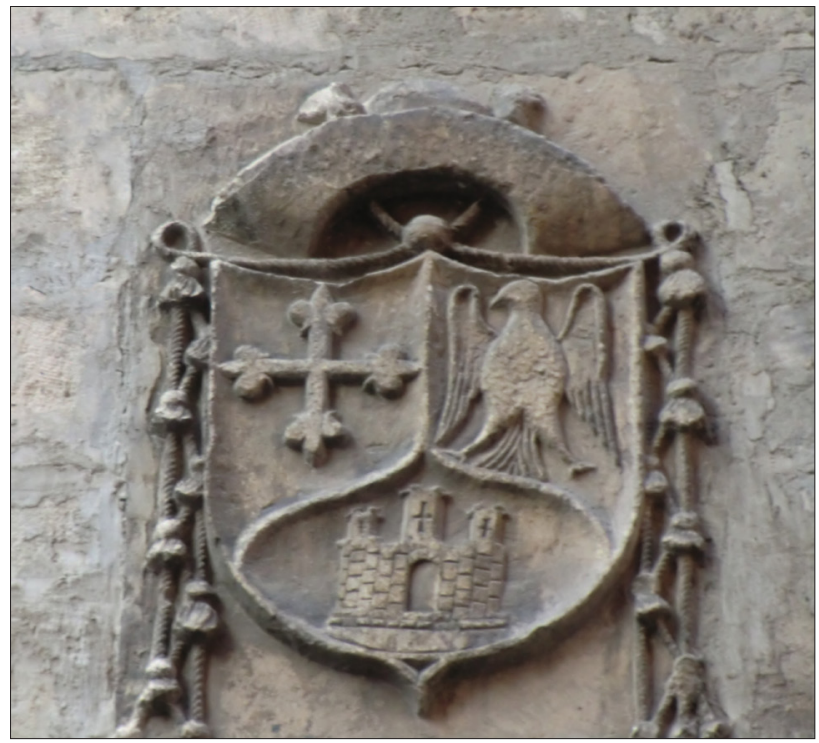

FOTO 2: EL EMBLEMA HERÁLDICO DE DON JUAN ARIAS DE ÁVILA, OBISPO DE SEGOVIA, EN LA FACHADA DEL HOSPITAL DE LOS SANTOS COSME Y DAMIÁN, HOY EN LA RESIDENCIA SACERDOTAL DEL ARZOBISPADO DE VALLADOLID

Puñonrostro, no al antepasado concreto del siglo XV. Después, falta la tau en la puerta del castillo del cuartel inferior y, obviamente, no está la orladura que sólo se incorporó al blasón familiar cuando los descendientes de Pedrarias fueron los cabeza de linaje. Recordemos que el primer conde de Puñonrostro no la portaba al haber heredado las primitivas ${ }^{73}$.

De esta manera, la alusión genérica a sus antecesores pudiera entenderse como conciencia de parentesco, si bien conllevaba una cierta reconstrucción

72. ACP, PU, 61-24b, 1630, diciembre, 11. Valladolid; los testigos fueron Juan del Barco, escribano del rey, el licenciado Bartolomé Santos, clérigo, y Manuel de Riaza, vecinos en Valladolid.

Se puede consultar la fotografía de la fachada y la reconstrucción del plano viario de Valladolid con el enclave del hospital e iglesia del Rosario en: <http://www.valladolidweb.es/valladolid/loqueyanoesta/hospitaldelrosario.htm> consultado por última vez día 29 de abril de 2019.

73. Contreras Jiménez, M. ${ }^{a}$ Eugenia, Linaje y transición histórica..., pp. 361-379. 
de la memoria al identificar en las armas del establecimiento a los Puñonrostro, cuando la vinculación provenía por el mayorazgo del obispo ${ }^{74}$.

Aunque no se conozcan las motivaciones que llevaron a la redacción del documento de i630, se percibe la reivindicación de las relaciones existentes entre el hospital -no la cofradía, no mencionada- y la familia Arias Dávila.

En el siglo XVII es preciso considerar un hecho muy significativo para el linaje: en 1635 se produce la venta de una de las señas de identidad del mayorazgo configurado por Pedrarias, las casas principales situadas en la plaza de San Esteban en Segovia ${ }^{75}$. Es muy posible que el último morador de las mismas fuese Diego Arias de Rojas, ya que los intereses familiares de los condes de Puñonrostro siempre estuvieron allende del Sistema Central. Dado el predominio que en el conjunto familiar presentaba el condado, dirigido por personajes vinculados a la corte real, pesó más la localización geográfica de ésta y de las posesiones entre Madrid y Toledo, que los dominios alejados físicamente que, sobre todo, eran costosos de mantener ${ }^{76}$.

\section{LA EVOLUCIÓN DE LA MEMORIA DEL LINAJE}

El linaje Arias Dávila carece de una obra literaria de exaltación, pero ha utilizado otras formas de memoria como la que nos ocupa. Con ella se materializa la presencia de individuos y de la familia de forma continuada en un espacio.

En mi opinión presentan sumo interés varias cuestiones. En primer lugar, quién fue el personaje que genera la memoria y qué tipo de conexión individual establece con la propia del linaje y con la cofradía y el hospital. Se distinguen diversos roles: el obispo don Juan fue el origen de las relaciones con la cofradía y con la dotación al concretar un espacio; Pedrarias, sin otorgarse notoriedad al seguir la voluntad de su tío, aseguró la perdurabilidad de la imagen del prelado como protector de aquélla y primó la beneficencia social; don Francisco Arias Dávila fortalece la imagen de su propio matrimonio, como hito en la evolución del linaje, en un hospital que ha comenzado una nueva etapa y se ocupa de una dotación ornamental estratégica; por último, don Gonzalo, llama la atención sobre los emblemas heráldicos familiares en la fachada del hospital, para reivindicar la relación con su

74. En relación con este asunto no puede dejarse de lado que no es posible determinar si la publicación que se había hecho en 1622 del Nobiliario Genealógico de los Reyes y Títulos de España de A. López de Haro, provocó los deseos de don Gonzalo Arias Dávila de recopilar aquellos elementos que identificaban a su linaje, en especial, después de los escritos de Herrera.

75. ACSg, G-7, 1767, octubre, 27. San Lorenzo [de El Escorial]; se dice que el conde de Puñonrostro había vendido en 1635 dichas casas a don Antonio de Salcedo.

76. Véase la venta de casas principales de mayorazgos en la Salamanca de la Edad Moderna en López BENITO, Clara Isabel y Rupérez AlmajANo, M. ${ }^{a}$ Nieves: «Aportación al estudio de la nobleza salmantina en la Edad Moderna a través de sus casas», Stvdia Historica. Historia Moderna, XI (1993), pp. 149-168, en especial pp. 163-4, que ven en ello un cambio de mentalidad de la nobleza que pasó a ser cortesana y a alejarse de sus lugares de origen. 
linaje. En la motivación personal de las donaciones, nunca explicitada, subyace el deseo de hacer presente a la dicha familia en ámbitos diferentes a aquéllos de origen y de demostrar la magnanimidad de la nobleza en su nexo con la Iglesia.

En segundo lugar, la memoria es generada a partir y sobre diversas acciones: comienza por la intervención en una arquitectura, evoluciona hacia la ayuda a los necesitados con la edificación de un hospital, para pasar a materializarse en ornamentos y emblemas heráldicos en el templo de éste. Sigue así pautas similares a las expresadas en otros linajes desde el siglo XV.

En tercero, se percibe la misma evolución en a quién se debe recordar: en un primer momento al obispo, en la decimoséptima centuria a su familia. No olvidemos que en este siglo la genealogía y sus cronicones alcanzaron gran importancia tanto para la nobleza como para las ciudades. Por tanto, no se remembran hechos gloriosos, sino que se realza unas relaciones de patronazgo individual y del linaje.

Por otro lado, durante el proceso analizado quienes debían guardar esa memoria eran los cofrades, ya que nunca consta referencia a que los beneficiarios del hospital tuvieran obligación alguna en este sentido.

Por último, los instrumentos que mantuvieron la memoria estaban centralizados y escenificados en el hospital de la cofradía. Así los emblemas heráldicos, seña del pasado familiar y de pertenencia, presentan dos tipos: los propios del obispo y los pertenecientes al conde de Puñonrostro, cuando ya se han fusionado los dos mayorazgos. Los primeros funcionaron como referente del origen del linaje tal y como quiso Pedrarias, mientras que los del Conde llamaban la atención sobre un individuo que expresa su deseo de continuidad de la relación entre su Casa y el hospital de los Mártires, y de perpetuidad con la cercanía del objeto donado al altar mayor, a la Divinidad, en esencia eterna. Así fusionaban en una sola imagen los dos estamentos privilegiados que sostuvieron el Antiguo Régimen.

Otros medios de transmisión de la memoria fueron vinculados al carácter sensorial de la misma. Pedrarias los estableció, primero, de forma visual en los emblemas heráldicos y en los túmulos de madera con el boato correspondiente a un obispo; después, auditiva, con la reiteración del nombre de don Juan y de su destacada posición en la Iglesia. En el siglo XVII está documentada exclusivamente la visual, enfocada hacia el linaje y sus emblemas heráldicos. Recordemos igualmente que en esta centuria los documentos dan realce a la parte pública de la cofradía: el templo de su hospital, donde estaba la lámpara donada y los escudos en la fachada.

Igualmente, pueden ser considerados instrumentos de remembranza los juramentos realizados por los cofrades en su nombre y el de sus sucesores, a fin de acatar los acuerdos establecidos con la familia Arias Dávila. La constante mención de estos sucesores implica una previsión para el futuro que debería tener en cuenta el pasado. 


\section{CONSIDERACIONES FINALES}

La documentación utilizada, al proceder en buena parte de un archivo nobiliar, nos indica qué tipo de acciones merecieron el interés del mayorazgo y de sus administradores en conservar aquellos instrumentos que suponían una memoria y conciencia de los antepasados y, al tiempo, unos ciertos derechos sobre la cofradía y hospital de los santos Cosme y Damián de Valladolid.

Los distintos Arias Dávila presentaron una actitud diferente y paralela a la evolución en el concepto de memoria y de presencia, si bien para todos ellos el vínculo con la cofradía y con el hospital indicaron un grado de distinción social, así como la memoria y antigüedad de su nobleza, de su poder económico y de su apoyo a la Iglesia.

En el devenir se aprecia una variación: desde asumir las ordenanzas de la cofradía a finales del siglo $\mathrm{XV}$ a la exhibición de los símbolos familiares en la propiedad más visible de la institución, el hospital, como un elemento más del condado, de su presencia y extensión por distintos ámbitos geográficos.

Sólo nos constan relaciones entre el cabeza de linaje y la institución, no pareciendo que hubiera conexiones con el sucesor en los mayorazgos. Recordemos que aquél era el eje central de la Casa, quien gestionaba las señas de identidad y aseguraba la memoria.

En lo referente al cabeza de la Casa, cuando ostentó en primer lugar el mayorazgo proveniente de Diego Arias y de Elvira González, el nexo con la cofradía tuvo para él una importancia secundaria, acentuada por la posición alejada de sus intereses geográficos: el Madrid cortesano y sus alrededores. De esta manera, se documenta la evolución de la mentalidad de un linaje según la posición que tuvieran unos bienes heredados en el conjunto socioeconómico del mismo.

Por otro lado, el impacto de las acciones de los miembros del linaje es muy distinta: la aportación económica proveniente de los bienes terrenales de don Juan Arias de Ávila permitió que la cofradía enfocase su acción hacia ese hospital erigido gracias a aquélla, pero, sobre todo, fue fruto de la voluntad personal de Pedrarias, que es el Arias Dávila con el que la cofradía llega a un acuerdo. Incluso, la acción de Pedrarias fue la que imprimió mayor huella en la ciudad, ya que todos los viandantes podían observar el nuevo edificio erigido en la trama urbana y los necesitados pudieron acogerse en la institución. Junto a esto, la lámpara supuso una menor inversión en términos económicos y en repercusión visual, ya que había que penetrar en la capilla para poder ser apreciada, si bien la localización nos habla de la cercanía a la Divinidad.

Las relaciones entre Arias Dávila y cofrades fueron cambiando, puesto que, en un primer momento, los contactos se realizan con la cofradía, pero luego es el hospital quien pasó a ser el centro de los mismos, quizá como resultado de la fusión con la del Rosario y por tanto, de una fuerte modificación de las características de una de las partes. Es preciso incidir en que el establecimiento de conexiones 
con la dicha cofradía supuso un contacto entre miembros seglares de la lglesia, no con la estructura clerical de la misma, situación que varió en el siglo XVII: Pedrarias asistió a la firma del contrato en Valladolid tratando directamente con la cofradía, con seglares; don Francisco Arias lo resuelve desde Madrid y trata con la cofradía a través de un sacerdote, miembro de la institución, pero eclesiástico. Todo ello debe de entenderse como una consecuencia más del fortalecimiento del clero en la Iglesia Católica frente a los seglares tras el Concilio de Trento y la reorganización que éste supuso en el seno de aquélla.

Finalmente, el tiempo ha hecho que sean los emblemas heráldicos de don Juan Arias que Pedrarias ordenó disponer en la fachada del hospital de San Cosme y San Damián de Valladolid, los que hayan sobrevivido hasta nuestros días gracias a que han pasado a la correspondiente de la Residencia sacerdotal de dicha ciudad.

Pedrarias ha conseguido, una vez más, que triunfe el recuerdo de su tío protector, el obispo de Segovia, don Juan Arias de Ávila. 


\section{BIBLIOGRAFÍA}

Agapito y Revilla, Juan: Las calles de Valladolid. Nomenclator histórico (I937), Valladolid, (I937, facsímil I982).

Agapito y Revilla, Juan: «La Capilla Real de Valladolid», Boletín de la Sociedad Española de Excursiones, año LII (I944), segundo trimestre, pp. II5-I44 e ibidem, tercer trimestre, pp. I6I-203.

Alcocer y Martínez, Manuel: «El Rosarillo», Boletín de la Comisión de Monumentos Históricos y Artísticos de la provincia de Valladolid, año III 5 [I927], pp. 33-47.

Alcocer y Martínez, Manuel: El Rosarillo. Estudio histórico de la cofradía de San Cosme y San Damian antes y después de su unión con la de Nuestra Señora del Rosario, Valladolid, Casa Social Católica, (s.a.).

Álvarez Rubiano, Pablo: Pedrarias Dávila. Contribución al estudio de la figura del «gran justador», Gobernador de Castilla del Oro y Nicaragua, Madrid, C.S.I.C., I944.

ARAM, Bethany: Leyenda negra y leyendas doradas en la conquista de América. Pedrarias y Balboa, Madrid, Fundación Jorge Juan-Marcial Pons, 2008.

Azcona, Tarsicio de (O.F.M. CAP.): Isabel la Católica, Madrid, Editorial Católica, I986.

Bernáldez, Andrés: Historia de los Reyes Católicos don Fernando y doña Isabel, Sevilla, Imprenta que fue de José María Geofrín, I870.

Cantero Muñoz, Antonio: «El patronato de Don Luis de Tapia y Paredes sobre la ermita de San Lázaro de Trujillo a partir de I630 y estatutos de su cofradía», XXXVII Coloquios Históricos de Extremadura: dedicados a la Guerra de la Independencia en Extremadura. Trujillo del 22 al 28 de septiembre de 2008, 2009, vol. 2, pp. 439-462.

Carrasco Martínez, Adolfo, «Los Mendoza y lo sagrado. Piedad y símbolo religioso en la cultura nobiliaria», Cuadernos de Historia Moderna, 25 (2000), pp. 233-269.

Carrete Parrondo, Carlos: Proceso inquisitorial contra los Arias Dávila segovianos: un enfrentamiento social entre judíos y conversos, Salamanca, Universidad de SalamancaUniversidad de Granada, I986.

Colmenares, Diego de: HISTORIA/ De La Insigne Ciudad/ DE SEGOVIA/y Conpendio de las Historias/DE CASTILLA/.../EN MADRID POR DIEGO DIEZ. INPRESOR. A COSTA DE SU AVTOR, I640.

Contreras Jiménez, María Eugenia: «Las fortalezas del Obispo de Segovia: Turégano y Lagunillas», Castillos de España, 95 (1988), pp. 59-66.

Contreras JimÉnez, María Eugenia: Linaje y transición histórica. Los Arias Dávila entre el Medievo y la Modernidad, tesis doctoral presentada en la Universidad Complutense de Madrid, (2018).

DAcosta, Arsenio: «A propósito de un aparente silencio: la memoria genealógica escrita de la nobleza peninsular en la baja Edad Media», Tiempos modernos, 32 (2016/I), pp. 73-87.

Dacosta, Arsenio; Prieto Lasa, José Ramón; Díaz De Durana, José Ramón (eds.): La conciencia de los antepasados. La construcción de la memoria de la nobleza en la Baja Edad Media, Madrid, Marcial Pons Historia, 2014.

EGIDO, Teófanes: «Religiosidad popular y asistencia social en Valladolid: Las cofradías marianas del siglo XVI», Estudios marianos, 45 (I980), pp. I97-2I7.

Egido, Teófanes: «Formas de religiosidad en la época moderna», Valladolid. Historia de una ciudad: congreso internacional, II, [Valladolid], Ayuntamiento de Valladolid, [1999], pp. 5II-524. 
EnCiso Recio, Luis Miguel: «Apuntes sobre religiosidad y secularización de costumbres en Valladolid a comienzos del siglo XVII», en Estudios en homenaje al profesor Teófanes Egido, Sobaler Seco, M. a de los Ángeles y García Fernández, Manuel (coords.), II, Valladolid, Junta de Castilla y León, 2004, pp. 5I-72.

FernÁndez DEl Hoyo, M. a Ángeles: Conventos desaparecidos de Valladolid: patrimonio perdido, Ayuntamiento de Valladolid, 1998.

Gutiérrez Alonso, Adriano: Estudio sobre la decadencia de Castilla. La ciudad de Valladolid en el siglo XVII, Valladolid, Universidad de Valladolid, I989.

GutiérRez Alonso, Adriano: «El siglo XVII», en Historia de Valladolid, Valdeón BarUQUE, Julio (ed.), Valladolid, Ámbito, I997, pp. I3I-I54.

Gutiérrez Alonso, Adriano, Martín GonZález, Juan José, Urrea, Jesús, Rubio GonZález, Lorenzo, Virgilı Blanquet, M. ${ }^{a}$ Antonia: Valladolid en el siglo XVII, Historia de Valladolid, IV, Valladolid, Ateneo de Valladolid, I982.

JaRA Fuente, José Antonio: «Muerte, ceremonial y ritual funerario: Procesos de cohesión intraestamental y de control social en la alta aristocracia del Antiguo Régimen (Corona de Castilla, siglos XV-XVIII)», Hispania. Revista Española de Historia, I94 (I996), pp. 86I-883.

Jular Pérez-Alfaro, Cristina: «La importancia de ser antiguo: Los Velasco y su construcción genealógica», en Dacosta, Arsenio; Prieto Lasa, José Ramón; Díaz de durana, José Ramón (eds.), La conciencia de los antepasados. La construcción de la memoria de la nobleza en la Baja Edad Media, Madrid, Marcial Pons Historia, 20I4, pp. $20 \mathrm{I}-236$.

Larruga, Eugenio: Memorias Políticas y Económicas... de la ciudad de Valladolid, T. XXIII, En Madrid por Don Antonio Espinosa, Año MDCCXCll.

Lecea y García, Carlos de: «Memorial histórico de Segovia, escrito por don Juan de Pantigoso en I523», B.R.A.H., XIV, (I889), pp. 2I2-26I.

LE FLEM, Jean-Paul: «La première version castillane du testament de don Juan Arias Dávila, évêque de Segovie», EE.SS., XXII (I970), pp. I7-46.

López Benito, Clara Isabel y Rupérez AlmajAno, M. ${ }^{a}$ Nieves: «Aportación al estudio de la nobleza salmantina en la Edad Moderna a través de sus casas», Stvdia Historica. Historia Moderna, XI (I993), pp. I49-I68.

Martín Ortega, Alejandro: Historia de la villa de San Agustín, Madrid, I954.

Martínez Martínez, M. ${ }^{a}$ del Carmen: «Pro defensione veritatis: Antonio de Herrera, Cronista Mayor de Indias », e-Spania [En ligne], I8 | juin 2014, mis en ligne le 26 février 2018; consultado el día 24 de abril de 2019 por última vez. URL: $<$ http://journals.openedition. org/e-spania/23687; DOI : I0.4000/e-spania.23687>.

Mena García, M. ${ }^{\text {a }}$ del Carmen: Un linaje de conversos en tierras americanas: (los testamentos de Pedrarias Dávila, Gobernador de Castilla del Oro y Nicaragua), Salamanca, Universidad de León, 2004.

Montero Tejada, Rosa María: Nobleza y sociedad en Castilla: El linaje Manrique (siglos XIVXVI), Madrid, Caja de Madrid, I996.

Nogales Rincón, David: «El color negro: luto y magnificencia en la Corona de Castilla (siglos XIII-XV)», Medievalismo, 26 (20I6), pp. 22I-245.

Palencia, Alonso de: Crónica de Enrique IV, Paz y Meliá, Antonio (ed.), Madrid, B.A.E., CCLVII-CCLIX, I973-5.

Pérez GonzÁlez, Silvia M. ${ }^{\text {a }}$ : «Nuevas aportaciones al estudio de las cofradías y hermandades en la Castilla bajomedieval: el ejemplo de Jerez de la Frontera», Hispania Sacra, I38 (2016), pp. 503-520.

RODRíguez EsPINOZA, Arnaldo: «Vinculaciones religiosas, milicias y cabildo: el linaje Viales Briceño en el partido de Nicoya (I768-I824)», Espiga, 30 (julio-diciembre 20I5), pp. 83-96. 
RodríGuez Morales, Carlos: «Iglesia y sociedad en La Laguna durante el Antiguo Régimen. La cofradía de Jesús Nazareno y el patronato de los Salazar de Frías», Revista de Historia Canaria, I83 (abril, 200I), pp. 275-293.

Romero Mensaque, Carlos José: «Los comienzos del fenómeno rosariano en la España Moderna. La etapa fundacional (siglos XV-XVI)», Hispania sacra, LXVI (20I4), Extra II, pp. 243-278.

Silva PRADA, Natalia: «La dote en la familia devocional: estrategias familiares en la cofradía novohispana, I538-I680», Anuario de historia regional y de las fronteras, vol. 6, I (200I), pp. 419-445.

Synodicon Hispanum VI, García y García, Antonio (dir.), Madrid, B.A.C., I993.

Valladolid. Historia de una ciudad: congreso internacional: II, Valladolid, Ayuntamiento de Valladolid, [1999]. 

Calidad de Revistas

Científicas Españolas

FECYT |
SERIE III HISTORIA MEDIEVAL

REVISTA DE LA FACULTAD DE GEOGRAFÍA E HISTORIA
AÑO 2020

ISSN: 0214-9745

E-ISSN 2340-1362

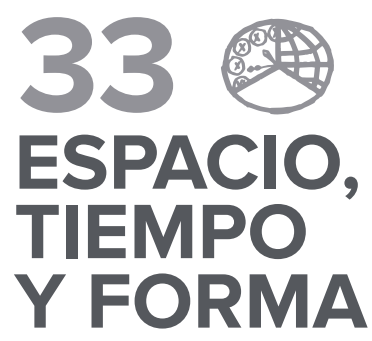

\section{Artículos · Articles}

7 FREDERIC APARISI ROMERO

El cultivo y procesado del lino en el Reino de Valencia (ss. XIII-XVII)

13 ADRIÁN CALONGE MIRANDA

El mantenimiento del entramado viario romano en época medieval en La Rioja. Algunos casos de estudio

\section{Miguel Calleja Puerta}

Notarios públicos entre dos reinos. Apuntes diplomáticos sobre documentos notariales castellanos en el Arquivo Distrital de Braga

\section{Xavier Casassas Canals}

Las 'aqida-s entre los musulmanes castellanos y aragoneses de época mudéjar y morisca: Las 'aqĩda-s de Ibn Abi Zayd Al-Qayrawāni (s. X), Ibn Tümart (s. XII) e Isa de Jebir (s. XV)

\section{ARCADIO DEL CASTILLO}

Sobre el Códice Alcobacense de Vaseo y los Annales Portugalenses Veteres: Continuidad del reino visigodo de Toledo

\section{Paula Castillo}

Las formas de la violencia entre frailes. El testimonio de Fray Ubertino de Casale

\section{María Eugenia CONTRERAS JIMÉnEZ}

La memoria del linaje Arias Dávila en la cofradía y hospital de San Cosme y San Damián de Valladolid (siglos XV a XVII)

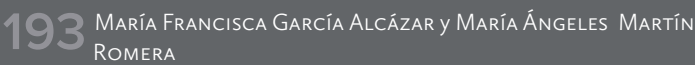
Entre servicio regio y estrategia personal: Los Continos de Valladolid (1480-1525)

\section{César García de Castro Valdés y josé Antonio Valdés
Gallego}

Las inscripciones perdidas de la basílica altomedieval de San Salvador de Oviedo

\section{María José Lop OtÍN}

Hay tal número de clérigos que causa asombro. La clerecía de Toledo a fines de la Edad Media

\section{CORINA LUCHÍA}

Por que los montes de esta villa se conserben, e no se disipen como al presente estan: La regulación de los recursos forestales en la Corona de Castilla (siglos XIV-XVI)
333 María Encarnación Martín López

Las inscripciones medievales del claustro de la catedral de Roda de Isábena (Huesca). Aproximación a su taller lapidario

\section{ISABEL MONTES ROMERO-CAMACHO}

Los archivos catedralicios y su importancia para los estudios prosopográficos. El deán Don Aparicio Sánchez, en el Archivo de la Catedral de Sevilla

\subsection{Gonzalo Oliva Manso}

La moneda en Castilla y León (1265-1284). Alfonso X, un adelantado a su tiempo.

4.73 Mariana Valeria Parma

Entre los signos del cielo y las voces de los hombres: La visión medieval del cielo y su representación apocalíptica

\section{Milagros Plaza Pedroche \\ Los maestres santiaguistas y su designación regia durante el} reinado de Juan I de Trastámara (1379-1390): La legitimación del proceso

521 Juan A. Prieto Sayagués

La profesión de las élites castellanas en los monasterios y conventos durante la Baja Edad Media

\section{EnRIQUe José RuIz PILARES}

La funcionalidad social de los inmuebles urbanos de las élites dirigentes bajomedievales: Reflexiones a partir de un caso de estudio (Jerez de la Frontera, España)

\section{Gilberto SORIANO Calvo}

Influencia de las redes nobiliarias en la expansión cristiana del siglo XII. El caso de Soria

Mohammed S. TawfiQ, AlmudenaArizaArmada, Atef Mansour Mohammad, Ahmed Ameen y Mervat Abd EL-HadyAbdEL-Latif A Historical and Numismatic Study of the Dinars of the Ghaznavid Sultan Mahmūd B. Sabuktakin at Nishapur

653 JOSÉ LUIS DE VILLAR IGLESIAS

Los aspectos económicos en la Batalla por el Magreb entre omeyas y fātimíes: El control del acceso al oro del Sudán Occidental

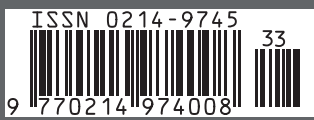




\section{3}

\section{ESPACIO,}

\section{TIEMPO}

Y FORMA

UกED

SERIE III HISTORIA MEDIEVAL

REVISTA DE LA FACULTAD DE GEOGRAFÍA E HISTORIA

\section{Libros · Books}

679 Bello León, Juan Manuel y ORTEgo Rico, Pablo, Los agentes fiscales en la Andalucía Atlántica a finales de la Edad Media: Materiales de trabajo y propuesta de estudio (ANA MARÍA RIVERA MEDINA)

683 Calleja Puerta, Miguel y Domínguez Guerrero, María Luisa (eds.), Escritura, notariado y espacio urbano en la Corona de Castilla y Portugal (siglos XII-XVII) (PALOMA CUENCA MuÑoz)

687 CASADO ALONSO, Hilario (coord.), Comercio, finanzas $y$ fiscalidad en Castilla (siglos XV-XVI) (ANA MARía RIVERA MEdINA)

691 Castro Correa, Ainoa y Rodríguez Sánchez, Manuel, Colección diplomática altomedieval de Galicia II. Documentación en escritura visigótica de la sede lucense (PALOMA CUENCA MUÑOZ)

695 García Fernández, Ernesto, García-Gómez, Ismael, Rodríguez FERNÁNDEZ, José, Urbanismo, patrimonio, riqueza y poder en Vitoria-Gasteiz a fines de la Edad Media e inicios de la Edad Moderna (ENRIQUE CANTERA MONTENEGRO)

699 LADERO QUESADA, Miguel Ángel, Ciudades de la España medieval. Introducción a su estudio (GISELA CORONADO SCHWINDT)

705 LADERo Quesada, Miguel Ángel, Los últimos años de Fernando el Católico 1505-1517 (CARLOS BARQuero GoÑI)

707 Martín GutiérRez, Emilio y Ruiz Pilares, Enrique José, El viñedo en Jerez durante el siglo XV. Un mercado de trabajo en torno al vino (ANa María Rivera MEDINA)

711 MONSALVO ANTÓN, José María, La construcción del poder real en la monarquía castellana (siglos XI-XV) (MARÍA Jesús FUENTE)

715 Pérez Rodríguez, Francisco Javier, Los monasterios del Reino de Galicia entre 1075 y 1540: De la reforma gregoriana a la observante (EnRIQue CANTERA Montenegro)

717 REIXACH SALA, Albert, Finances públiques i mobilitat social a la Catalunya de la Baixa Edat Mitjana. Girona, 1340-1440 (JuLIÁN DONADO VARA)

721 SÁNCHEZ SÁNCHEZ, Xosé M., Iglesia, mentalidad y vida cotidiana en la Compostela medieval (ENRIQUe CANTERA MONTENEGRO)

725 Val Valdivieso, M. ${ }^{a}$ Isabel del, Martín Cea y Juan Carlos, CARVAJAL de La Vega, David (coords.), Expresiones del poder en la Edad Media. Homenaje al profesor Juan Antonio Bonachía Hernando (José RAmón Díaz de DURANA ORTIZ de URBINA) 